Histologisches und embryologisches Institut der k. a. k. tierärztlichen Hochschule in Wien.

\title{
Beiträge zur Kenntnis des Baues und der Funktion der Lamellenkörperchen.
}

\author{
Von \\ Prof. Siegmund v. Schumacher. \\ Hierzu Tafel VIII und 4 Textfiguren.
}

\section{Einleitung.}

Die unmittelbare Veranlassung zu vorliegender Mitteilung gab mir eine Arbeit Wi chailows (7) über „Die Struktur der Va te r Pacinischen Körperchen und ihre physiologische Bedeutung:" auf die ich erst durch ein Referat im Anatomischen Zentralblatt aufmerksam gemacht wurde. Wichailow gelangt auf Grund des Nachweises von reichlichen Kapillaren im Inneren der VaterPacinischen Körperchen zu einer ganz ahnlichen Hypothese über die Funktion der Lamellenkörperchen, wie ich sie vor einiger Zeit ausgesprochen habe (12). Meine diesbezüglichen Auseinandersetzungen scheinen $\mathrm{Michailow}$ entgangen $\mathrm{zu}$ sein, was begreiffich erscheint, da die Überschrift der betreffenden Arbeit nicht vermuten liess, dass der Inhalt sich mit den Lamellenkörperchen beschäftigt. Daher möchte ich hier nochmals zu dieser Frage Stellung nehmen, um so mehr, als ich durch inzwischen angestellte Untersuchungen imstande bin, meine Hypothese über die Funktion der Lamellenkörperchen besser $z \mathfrak{u}$ begründen, als dies seinerzeit möglich war.

Michailow gibt zunächst eine historische Übersicht über die Entwicklung der Lehre vom Aufbau der typischen VaterPacinischen Körperchen, namentlich auch von der Art der Nervenendigungen im Innenkolben. Nach der Ansicht Michailows gehören die im Innenkolben $\mathrm{zu}$ findenden Kerne Wanderzellen an und der Innenkolben selbst stellt (ähnlich wie die interkapsulären Zwischenrăume) einen mit Blutserum angefüllten Hohlraum dar. Unter dem Einflusse verănderter Bedingungen, namentlich der Einwirkung von Reagentien, gerinnt das Blut- 
serum und kann in diesem Zustande Zellstrukturen vortäuschen. Das den Innenkolben ertüllende Blutserum stammt aus den im Innenkolben vorhandenen Blutkapillaren und ebenso dürften aus letzteren die Leukozyten ausgewandert sein. Eingehend befasst sich Michailow mit der Frage der Vaskularisation der Lamellenkörperchen.

Schon seit langem ist es bekannt, dass die VaterPacinischen Körperchen ihre eigenen Blutgefăsse besitzen.

So finden sich nach Kölliker (5) im Stiele und den benachbarten Teilen der Körperchen, weniger haufig am anderen Ende derselben, wo die Lamellen nicht seltell durch einen Längsstrang (Lig. intercapsulare) verbunden sind, einzelne feine Blutgefässverästelungen.

Ausführliche und vollkommen zutreffende Mitteilungen über die Gefässe der Vater-Pacinischen Körperchen machte schon Herbst (3) im Jahre 1848. „An den beiden Seiten der Körperchen liegen zwei Blutgefatsse, von denen das eine gross, das andere aber nur etwa $1 / 3$ so weit ist; zahlreiche Äste derselben dringen in die Obertlache und in die peripherischen Kapseln, zu deren besseren Versorgung das grössere Blutgefass einen Hauptzweig quer über die Mitte des Körperchens sendet. Ferner befindet sich ein ansehnliches arterielles Gefäss, als Begleiter der Nervenfaser, im Stiele. Dasselbe dringt in die Basis des Körperchens, nimmt an allen Windungen der Nervenfaser teil, gibt nach allen Seiten an die Kapselinterstitien Äste, welche durch Zellgewebe in ihrer Lage erhalten werden, sich wie andere Kapillargefasse, nach einem kürzeren oder langeren Laufe schlingenförmig umbiegen und gegen den Stiel zurückkehren. Der Stamm dieses Gefasses ist bis zum Boden der innersten Kapsel sichtbar." „Ein anderes Blutgefäss dringt in das peripherische Ende des Körperchens, erstreckt sich in gerader oder schräger Richtung gegen den oberen Teil des innersten Kapselsystems und gibt zahlreiche Äste an die ausseren Kapseln, welche zum Teil mit den vom zentralen Ende hier ihnen entgegenkommenden anastomosieren."

Nach Michailow beschaftigte sich in letzter Zeit mit der Frage der Gefassversorgung der $\mathrm{V}$ a te $\mathrm{r}-\mathrm{P}$ a $\mathrm{c}$ in i schen Körperchen Kowrygin im Laboratorium Dogiels und gelangte zu dem Schlusse, dass in die Innenkolben der Körperchen Kapillaren eindringen. Auf Grund solcher Praparate Kowrygins schreibt 
Dogiel, dass feine Arterienzweige mit den Nerven in jedes Körperchen eintreten und sich in Kapillaren auflosen; letztere dringen in die Zwischenräume zwischen den ausseren und den nach innen zu gelegenen Lamellen ein, ziehen sich hier auf eine ziemlich grosse Entfernung hin, oft sogar bis zur Hălfte der Länge des Körperchens und bilden ein feinschlingiges Netz. Ausserdem dringen eine bis zwei kleine Arterien in das Körperchen von seiten des Poles ein, welcher der Stelle des Nerveneintrittes gegenüberliegt (nicht selten in der Gegend des Lig. interlamellare), und zerfallen hier in Kapillaren, deren Schlingen auf eine kleine Strecke in die Zwischenriume zwischen den Aussenkapseln eindringen. Die beiden Kapillarsysteme können untereinander durch lange Anastomosen verbunden sein. Schliesslich lässt sich bei manchen Körperchen nachweisen, dass ein bis zwei Kapillarschlingen mit den Nervenfasern zusammengehen und diese bis zum Innenkolben begleiten, wobei sie sogar mitunter in den letzteren eindringen, sich jedoch nicht weiter als bis zum Anfangsteil desselben erstrecken.

Michailow gelang es bei der Katze (im Mesenterium, Pankreas und anderen Organen) durch Injektion nachzuweisen, dass in jedes Vater-Pacinische Körperchen in der Gegend der Nerveneintrittstelle Kapillaren eindringen, sich im Innenkolben verzweigen, verflechten, anastomosieren und so einen komplizierten Knäuel bilden. Dieser Knaluel hat der Form des Innenkolbens entsprechend eine längliche Gestalt und breitet sich hauptsatchlich in der Hälfte des Innenkolbens aus, die die Nerveneintrittstelle trăgt. Aber auch in der anderen Halfte des Körperchens sind Kapillaren vorhanden, die entweder $Z$ weige des beschriebenen Glomerulus darstellen oder vom entgegengesetzten Pole in das Körperchen eindringen; so dass in manchen Körperchen im Bereiche des ganzen Innenkolbens Kapillaren $z u$ finden sind. Michailow konnte aber in keinem Falle, trotz vollkommen gelungener Injektion, das Eindringen von Kapiliaren in das Kapselsystem eines Körperchens beobachten.

An der Obertläche der Lamellenkörperchen gelang Michailow der Nachweis eines feinen elastischen Fasernetzes.

Bezüglich der Funktion der Vater-Pacini schen Körperchen aussert sich Michailow folgendermassen: „Wir haben schon gesehen, dass in dem Innenkolben der Vater- 
Pacinischen Körperchen ein Knäuel von Blutkapillaren vorhanden ist. Aus diesen Kapillaren muss unter dem Einflusse ihres Blutdruckes das Blutserum in die benachbarten Gewebe transsudieren. Wir haben gleichfalls gesehen, dass in dem Innenkolben ebenfalls ein kompliziert gebauter Nervenendapparat des Körperchens vorhanden ist. Wenn wir nun annehmen, dass der Blutdruck in den Kapillaren aus irgend einem Grunde sich vergrössert, so können folglich einerseits die Kapillaren sich erweitern, andrerseits kann die Filtration des Blutserums aus ihnen in den benachbarten liaum einen intensiveren Charakter annehmen. Unserer Meinung nach muss der eine, sowie auch der andere Umstand unbedingt als Erreger des Nervenendapparates des Vater-Pacinischen Körperchens dienen, wobei, dank der unmittelbaren Berührung zwischen diesem Nervenendapparat und dem (ilomerulus der Blutkapillaren, d. h. dank der angenassten Struktur der Körperchen, sogar die minimalsten Schwankungen des Blutdruckes in diesen Kapillaren durch die $\mathrm{Vater}$ Pacinischen Körperchen leicht wahrgenommen und registriert werden können." „Das aus dem Glomerulus der Blutkapillaren in den Hohlraum transsudierende und von hier wiederum in die interkapsulären Zwischenräume durchdringende Blutserum ist imstande, das Körperchen so weit auszudehnen, als es die Elastizitït des beschriebenen Netzchens gestattet. Dank der Anwesenheit dieses Netzchens geschieht es, dass alle Hoblriume des Körperchens beim variierenden Quantum des das letztere ausfüllenden Blutserums stets durch dieses vollständig ausgefüllt sind."

Demnach scheint Michailow die Hypothese sehr wahrscheinlich, „dass die typischen $\mathrm{V}$ ater-Pacinischen Körperchen solche Nervenendapparate vorstellen, welche Registratoren des Blutdruckes in den Kapillaren (und folglich auch im ganzen Blutgefä(3system) sind, d. h. als Anfänge des zentripetalen Weges desjenigen Reflexbogens erscheinen, dank welchem die Regulation des Blutdruckes verwirklicht wird."

Schon vor langerer Zeit glaubte Thoma (14) die von ihm in allen Teilen des Aortensystems gefundenen $\mathrm{Vater-Pacinischen}$ Körperchen als Regulationsvorrichtungen des Gefässtonus ansprechen zu dürfen. Allerdings stellt sich Tho ma die Einwirkung des Füllungsgrades der Gefüsse auf die Nervenendigungen in den Lamellenkörperchen wesentlich anders vor als Michailow. 
Thoma äussert sich diesbezüglich folgendermassen: „Dieselben (erg. Pacinischen Körperchen) liegen in den aussersten Zonen der Adventitia oder unmittelbar nach aussen von dieser. Sie erscheinen demgemåss vorzüglich geeignet, die leisen Vibrationen, die jeder strömenden Bewegung zukommen, zu perzipieren und als Nervenerregungen auf die Gefussmuskeln überzuleiten."

Auch Rainer (8) spricht in einer jüngst erschienenen kurzen Mitteilung über besonders modifizierte Vater-Pacinische Körperchen, die retroperitoneal zwischen der Wurzel des Mesocolon transversum und Mesenterium im adventitiellen Gewebe der grossen Venen gelegen sind, den Gedanken aus, dass diese Körperchen zu dem Füllungsgrade der Venen in funktioneller Beziehung stehen.

Nach Van de Velde (15) tritt in den basalen Pol der Vater-Pacinischen Körperchen meistens eine kleine Arterie ein, welche sich in interkapsuläre Kapillaren teilt. Aus dem Bau und der Lage der Körperchen ist zu entnehmen, dass diese besonders für Druck empfindlich sind. "Auch jhre Lage im Pankreas lässt hierauf schliessen: Wenn dieses seine Wirkung entfaltet, erweitern sich die Blutgefïsse des Organs und üben schon hierdurch einen Druck auf die in dieser Drüse gelegenen Körperchen aus. Dieser Druck ist jedoch nicht nur extrakapsulär vorhanden; er wird auch interkapsular gerade durch die früher genannten in die Körperchen eintretenden Kapillaren hervorgerufen, sei es, dass die Nervenendigung gedrückt wird durch die Ausdehnung von den Kapillaren allein, sei es, dass eine Vermehrung der interkapsulären Flüssigkeit durch grössere Blutzufuhr entstelt und diese einen grösseren Druck zustande bringt. In beiden Fällen kann dann ein Reflex auf andere Digestionsorgane vom Pankreas aus ausgelöst werden."

Aus diesen Angaben geht hervor, dass in letzter Zeit sich die Auffassung über die Funktion der Vater-Pacinischen Körperchen, wenigstens bei einigen Autoren, insofern geändert hat, als die Körperchen nicht mehr im gewöhnlichen Sinne des Wortes als Drucksinnesorgane aufgefasst werden, sondern ihnen bei der Regulierung des Blutdruckes eine wichtige Rolle zugeschrieben wird. In diesem Sinne habe ich mich schon vor dem Erscheinen der zitierten Arbeiten von Michailow, Rainer und Van de Velde ausgesprochen. 
Ich machte seinerzeit auf das Vorkommen von kleinen Lamellenkörperchen in der Nithe des von mir als arterio-venöse Anastomose (resp. als eine Gruppe von solchen) erkannten Glomus coccygeum des Menschen ${ }^{1}$ ) und in der (allerdings nicht unmittelbaren) Nachbarschaft der dem Glomus coccygeum bei Saugetieren entsprechenden Glomeruli caudales aufmerksam. Gewöhnlich liegen diese in kleineren oder grösseren Gruppen beisammen und speziell beim Menschen kommen in der Gegend des Glomus coccygeum kleine Lamellenkörperchen vor, die oft in grosser Anzahl eng aneinanderliegend von einer dichten fibrösen gemeinsamen Kapsel umgeben sind. Diese Lagebeziehung der Lamellenkörperchen zu den arterio-venösen Anastomosen liess an eine funktionelle Beziehung zwischen ersteren und letzteren denken, namentlich nachdem in der Năhe der arterio-venösen Anastomosen an den Endphalangen der Fledermäuse ebenfalls das Vorkommen von Gruppen Vater-Pacin ischer Körperchen nachgewiesen worden war. Diesbezüglich hatte schon Grosser (1) vor mir den Gedanken eines funktionellen Zusammenhanges zwischen Lamellenkörperchen und Anastomosen ausgesprochen, indem er glaubt, dass erstere als eine Art Indikator für den Füllungsgrad der Anastomose funktionieren könntell.

Ich schrieb seinerzeit über die mutmassliche Funktion der in der Nahe von arterio-venösen Anastomosen gelegenen Lamellenkörperchen folgendermassen: „Mir scheint die Annahme ebenfalls plausibel, dass diese Nervenendkörperchen funktionell mit den Anastomosen in Beziehung stehen. Es ware dieser Zusammenlang vielleicht in der Art denkbar, dass die Lamellenkörperchen eine Art von Feuchtigkeitsregulatoren darstellen. Es dürfte zugunsten dieser Anschauung auch der Bau der Lamellenkörperchen sprechen. Die Hülle besteht bekanntlich aus einer grossen Anzahl von ineinander geschachtelten Kapseln, die Bindegewebsfasern und Flüssigkeit enthalten. Würde nun aus irgend einem Grunde der Druck im Kapillargebiete steigen, so warre die nächste Folge eine stärkere Transsudation von Flüssigkeit aus den Kapillaren, eine stärkere Durchfeuchtung des Gewebes. Liegen im Bereiche der stärker durchfeuchteten Stelle Lamellenkörperchen, so würden ihre Kapseln Flüssigkeit aufnehmen, starker verquellen und dadurch

1) Beim Menschen hatten in der Gegend des Glomus coccygeum schon vor mir L us chka, W alker und S toerk Lamellenkörperchen gesehen. 
einen Druck auf den Innenkolben resp. auf den Achsenzylinder ausüben. Dieser Nervenreiz könnte auf die Vasomotoren übertragen werden und diese würden die Anastomosen erweitern, so dass die Nebenschliessung zwischen Arterie und Vene hergestellt wird und der Druck im entsprechenden Kapillargebiet sinkt. Aber auch dort, wo keine Anastomosen vorhanden sind, wäre an die Möglichkeit einer ahnlichen Funktion der Lamellenkörperchen zu denken, an eine Quellung bei stärkerer Durchfeuchtung und an eine reflektorische Beeinflussung der Gefässweite in der Art, dass der Blutdruck sinkt. Mir scheint diese Hypothese der Funktion der Lamellenkörperchen eher annehmbar zu sein, als ihre ihnen gewöhnlich zugeschriebene Bestimmung, dem Drucksinne zu dienen. In gewissem Sinne würden sie ja auch nach meiner Hypothese als Druckkörperchen wirken, indem auch ich mir vorstelle, dass die Nervenendigungen in den Körperchen durch Druck erregt werden, nämlich durch den Druck, den die Lamellen infolge ihrer grösseren Flüssigkeitsaufnahme, infolge ibrer Verquellung ausüben. Namentlich scheint diese Auffassung durch die für gewöhnliche Drucksinnesorgane schwer verständliche Lokalisation der Vater-Pacinischen hörperchen gestützt."

Aus dem Vergleiche der oben ausführlich wiedergegebenen Ansicht Michailows und meinen seinerzeit gemachten Ausführungen ergibt sich ohne weiteres die Übereinstimmung in unserer Auftassung von der Funktion der Lamellenkörperchen. Der einzige nennenswerte Unterschied besteht darin, dass Michailow annimmt, dass eine Flüssigkeitstranssudation aus den im Innenkolben selbst gelegenen Kapillaren stattfindet und eventuell die Erweiterung der Kapillaren direkt auf die Nervenendigungen im Innenkolben einwirken kann, während ich mir vorstellte, dass die Gewebsflüssigkeit von aussen her in die Körperchen eindringt und sie zur Aufquellung bringt. Ich hatte seinerzeit das Vorkommen von Blutgefassen in den Lamellenkörperchen nicht beachtet, möchte aber erwähnen, dass nach dem Nachweis eines Kapillarknäuels im Inneren des Körperchens der Gedanke Michailows auch mir naheliegend erscheint, dass namlich bei steigendem Blutdruck in den Kapillaren zunächst Flüssigkeit in die Lamellenräume transsudiert und so einen Druck auf die Nervenendigungen ausübt. Unterstützend dürfte dabei der in der Umgebung der Körperchen herrschende Flüssigkeits- 
druck insofern wirken, als bei grösserem Aussendruck eine Diffusion von Flüssigkeit aus dem Körperchen in das umgebende Gewebe verhindert wird oder bei geringer Flüssigkeitsmenge in den ausseren Lamellenräumen von aussen her in diese Flüssigkeit diffundiert. Schliesslich dürfte auch noch die ausserordentlich innige Anlagerung der Körperchen an grössere Gefasse (Arterien, Venen und Lymphgefasse), wie sie ausnahmslos im Mesenterium der Katze zu finden ist, funktionell von Bedeutung sein. Diese Lagerung ist derart, dass bei einer Erweiterung der Gefässe ein direkter Druck auf die Körperchen ausgeübt werden muss.

\section{Die Lamellen und der "Innenkolben" der Vater- Pacinischen Körperchen.}

Nach Key und Retzius (4) erscheinen die Kapsellinien der Vater-Pacinischen Förperchen oft nur einfach; nach Behandlung mit Osmiumsäure sieht man sie indessen sich der Länge nach in zwei spalten. Die Kerne liegen im Innern der durch die Spaltung entstandenen Raume, an der Obertläche der Wandhäutchen, die den Spaltraum begrenzen. „Diesen Strukturverhältnissen zufolge mag man nicht, wie von den Verfassern bisher geschehen ist, als Kapseln die oben erwähnten Kapsellinien betrachten; eine Kapsel ist nach unserer Auffassung der die albuminhaltige Flüssigkeit und die feinen Fibrillen enthaltende Raum mit seinen beiderseits begrenzenden, mit Zellenhäutchen bekleideten Wänden, welche, wenn ilırer zwei der angrenzenden Kapseln dicht beisammen liegen, im optischen Querschnitt als einfache Linien erscheinen können. Den die Flüssigkeit und die Fibrillen enthaltenden Raum selbst kann man einen Kapselraum oder Intrakapsularraum (den Interkapsularraum anderer Verfasser) nennen, wogegen die Räume zwischen den Kapseln Spaltenräume genannt werden können."

Diese Schilderung scheint mir nach meinen Untersuchungen vollkommen zutreffend zu sein. Haufig sieht man, wie sich Kapsellinien stellenweise spalten (Fig. 1 und 2, Taf. VIII) und erkennt dann, dass die Kerne in den so entstehenden Spalträumen liegen. Im übrigen ist färberisch in den Spalträumen kein Inhalt nachzuweisen, wăhrend in den Kapselräumen (Intrakapsularräumen) die Elüssigkeit je nach ihrem Eiweissgehalt eine schwächere oder intensivere Farbung annimmt. Des besseren Verständnisses halber sei auf das Schema Textfig. 1 verwiesen. 
Wir haben uns demnach die Kapseln (Lamellen) als mit Flüssigkeit gefüllte Hohlkapseln (Hohllamellen) vorzustellen, deren Wande von einem Bindegewebshäutchen und diesem obertlachlich aufgelagerten ganz flachen Zellen gebildet werden. Es ist wohl anzunehmen, dass intra vitam die Wandungen zweier benachbarter Lamellen so dicht aneinander liegen, dass zwischen ihnen kein Spaltraum vorhanden ist. Letzterer kann aber infolge der Einwirkung verschiedener Agentien postmortal auftreten, indem sich die Wandungen zweier benachbarter Kapseln von einander abheben, ein Zeichen, dass diese untereinander keinerlei Verbindung eingehen, wathrend die bindegewebigen Wandungen ein und derselben Kapsel untereinander durch verschieden stark ausgebildete Fibrillen oder Fibrillenbündel verbunden sind. Die Kapsellinien sind demnach als Doppellinien aufzufassen, erscheinen aber bei dichter Aneinanderlagerung einfach. Die Kapseln hatte man sich etwa in der Weise entstanden zu denken, dass sie zunächst als kompakte Bindegewebshautchen, deren Oberflachen mit endothelartigen Zellen bekleidet sind, auftreten. Im Innern dieser Bindegewebshautchen sammeit sich weiterhin Flüssigkeit an, so dass hierdurch die Randpartien der Hautchen mit den autliegenden Zellen auseinandergedringt werden und zwischen den beiden Randteilen der Lamellenraum entsteht. Als Zeichen des ursprünglichen Zusammenhanges der beiden nunmehr durch die Flüssigkeit auseinandergedrängten Randteile sieht man noch einzelne Fibrillen oder Fibrillenbündel, welche die beiden Wandungen einer Lamelle untereinander verbinden.

Wie schon erwalhnt, konnte Michailow an der Oberflache der Vater-Pacinischen Körperchen der Katze ein feines elastisches Netz nachweisen. Ein Körperchen würde sich nach Michailow so weit ausdehnen können, als es die Elastizitit dieses Netzchens gestattet. Infolge der Anwesenheit desselben sollen alle Hohlräume des Körperchens beim variierenden Quantum des das letztere ausfüllenden Blutserums stets durch dieses vollständig ausgefüllt sein.

Elastische Fasern in den Lamellen sind schon von Henle und Kölliker (2) gesehen worden. Sie erwähnen diesbezüglich, dass man bei Betrachtung von Kapselfragmenten bei stärkerer Vergrösserung ausser den Elementen des Bindegewebes häufig die blassen, geraden, stellenweise verästelten und in Essigsăure 
unlöslichen Fasern erkennen kann, welche in der Lamina fusca, Zonula Zinnii und an anderen Stellen vorkommen.

Nach Key und Retzius (4) sieht man oft, sowohl am GipfeI der Körperchen als auch am Stiel, besonders am Anfange des Innenkolbens, ringförmige Einschnürungen von circulären elastischen Fasern herrührend, welche in den Kapselhäutchen verlaufen. Diese Ringe sind vorzugsweise zu sehen, wenn die Kapseln eine Schwellung erlitten hatten.

Das von Michailow an der Obertläche der Lamellenkörperchen, d. h. in der Aussenwand der aussersten Lamelle gelegene elastische Netz lässt sich leicht nachweisen, sowohl an isolierten Körperchen durch die Einwirkung von Essigsïure, Kalilauge oder mit irgend einem Färbemittel für elastische Fasern, als auch an Schnitten. Besonders eignen sich hierzu nicht zu dünne, mit Resorcin-Fuchsin gefärbte Längsschnitte, die durch die Peripherie des Körperchens gehen, so dass ein Teil der Lamellen mehr oder weniger schräg getroffen ist. Am reinen Querschnitt durch die Lamellen sind die elastischen Fasern des Netzes allerdings auch in Form von feinsten Punkten $z u$ sehen, aber bei der Feinheit der einzelnen Fasern immerhin schwieriger nachzuweisen, als wenn die Lamellen mehr tangential getroffen sind. Bei günstiger Schnittrichtung lasst sich, ebenso wie am isolierten Körperchen, nachweisen, dass ein elastisches Fasernetz nicht nur in der Aussenwand der oberflüchlichsten Lamelle vorhanden ist, sondern auch in der Innenwand derselben und weiterhin noch in den Wänden von zwei bis drei nach innen folgenden Lamellen; allerdings werden die elastischen Fasernetze von der Obertlache gegen das Innere hin immer feiner und mit ResorcinFuchsin schwăcher farbbar. Die elastischen Fasern verlaufen gestreckt, zeigen eine etwas verschiedene Dicke, sind im allgemeinen aber als fein $z u$ bezeichnen und zeigen keine bestimmte Richtung.

Was den "Innenkolben" betrifft, so will ich hier nicht alle verschiedenen Angaben, die diesbezüglich gemacht wurden, wiederholen, sondern nur die wichtigsten Anschauungen über den Bau desselben herausgreifen. Eingehende Literaturangaben finden sich bei Key und Retzius (4) und bei Merkel (6).

In letzter Zeit wird mit Recht ziemlich allgemiein angenommen, dass im Innenkolben der Lamellenkörperchen keine „sekundären Sinneszellen" vorkommen. 
Nach Kölliker (5) ist der Innenkolben ein heller, feinkörniger und mit zarten Kernen (Zellen?) versehener weicher Strang, der als eine Art einfacher Bindesubstanz aufzufassen ist, um so mehr, als er wenigstens in seinen ausseren Teilen wie aus zarten, dicht beisammen liegenden Kapseln zu bestehen scheint.

R a uber (9) bemerkt bezüglich des Innenkolbens folgendes: „Ich selbst sah im Innenkolben einer grösseren Zahl von Vat erschen Körpern des Menschen, der Katze und des Kaninchens sowohl Kerne als Längsstreifen. Die Kerne sind sehr deutlich beim Kaninchen. In manchen Fällen lassen sich von diesen ausgehend Streifenfortsätze erkennen. Die Längsstreifen waren bei allen drei Arten in einzelnen Fallen und wenn die Kerne sich nur spärlich vorhanden zeigten, sehr ausgeprägt und konnten deren fünf bis neun jederseits gezahlt werden. In einer anderen Reihe von Körpern war der Innenkolben infolge der allmällichen Abnahme der Dicke der Kapseln von dem inneren Kapselsystem nicht scharf abgegrenzt und konnte man zwischen $z$ wei, drei und vier Streifen wählen, welche den Anfang des Innenkolbens darstellen sollten."

Nach Key und Retzius zeigt der Innenkolben hier und da eine Längsstreifung mit lingsgehenden kleinen Spalten, wie auch eine konzentrische Anordnung, aber keine weitere Fibrillierung, sondern ist schwach körnig.

Im Lehrbuche der Histologie von Stöhr (13) wird der Innenkolben als eine feinkörnige Masse beschrieben, welche konzentrische Schichtung zeigt und an der Peripherie spirliche Kerne aufweist.

Wie schon einleitend bemerkt, bält Michailow in Übereinstimmung mit einigen anderen Autoren den Innenkolben für einen mit Blutserum angefüllten Hohlraum und die in diesem vorkommenden Kerne für Kerne von Wanderzellen, welche aus den Kapillaren im Innern des Körperchens ausgewandert sein dürften.

Eingehender muss ich mich mit den Angaben Merkels über den Bau des Innenkolbens befassen, da sie den von mir erhobenen Befunden sebr nahe kommen, ja in den Hauptpunkten mit diesen vollkommen übereinstimmen. Me rk el bezeichnet den Innenkolben der Autoren seiner Struktur nach als , inneres Lamellensystem ${ }^{*}$. In dem inneren Lamellensystem der 
Vaterschen Körperchen der Yögel sieht man am Querschnitt an den beiden Schmalseiten der bandartigen Nervenfaser die zu zwei Reihen angeordneten Kerne und erkennt, wie aus dem sie umgebenden sehr spärlichen Protoplasma die Lamellen hervorgehen. „Man hat also Halbrinnen vor sich, welche durch die beiden Zellenreihen zusammengehalten werden. Kennt man diesen Bau, dann erklärt sich auch die Lăngsstreifung ganz einfach als der optische Durchschnitt der übereinander liegenden Lamellen." Auch bei den Krause schen Endkolben der Saugetiere ist der „Innenkolben“ nach Merkel nichts anderes, als ein System von übereinander gelagerten Lamellen und es tritt die Lăngsstreifung meist weit schärfer hervor als bei den Vaterschen Körperchen der Vögel. Querschnitte zeigen die einzelnen Lamellen sehr deutlich. Letztere bilden auch hier keine Röhren mit ringförmigem Durchschnitt, obgleich dickere und schief ausgefallene Schnitte oft genug solche vortăuschen. „Von den Schmalseiten der Terminalfaser geht auf feinen Querschnitten ein streifenförmiger Kontur aus, an welchen die Lamellen herantreten. Man kann ihn nach seinem Aussehen am besten mit dem Namen ,Raphe bezeichnen." Die Vaterschen Kiörperchen der Säugetiere zeigen genau das innere Lamellensystem wie die bisher beschriebenen Körperchen. „Besieht man feine Querschnitte sorgfaltig gehärteter Körperchen, dann fällt auf den ersten Blick die lamellöse Schichtung und die von beiden Seiten der Terminalfaser ausgehende Raphe auf. Auch erkennt man stets in den ausseren Lamellen Kerne, welche nach der Spezies in grösserer oder geringerer Menge vorhanden sind." Soweit die Darstellung Merkels über den "Innenkolben".

An Querschnitten durch Lamellenkörperchen aus dem Mesenterium der Katze, worauf sich meine Untersuchungen zunächst beziehen, konnte ich in Übereinstimmung mit Merkel nachweisen, dass die Lamellen bis an den zentralen Achsenzylinder heranreichen, so dass zwischen letzterem und den innersten Lamellen kein Spaltraum übrig bleibt, der etwa als Innenkolben gedeutet werden könnte. Die innersten sechs bis zwölf unmittelbar dem zentralen Achsenzylinder aufgelagerten schmalen Lamellen zeigen aber gegenüber den weiter peripher folgenden einen auffallenden Unterschied (siehe das Schema Textfig. I und Fig. 1 und 2, Taf. VIII). Sie erscheinen am Querschnitt nămlich nicht 
als geschlossene Reife, wie dies schon Nerkel richtig erkannt hat, sondern sichelförmig, also als Halbreife, deren etwas zugespitzte Enden nicht in die der Halbreife der anderen Seite

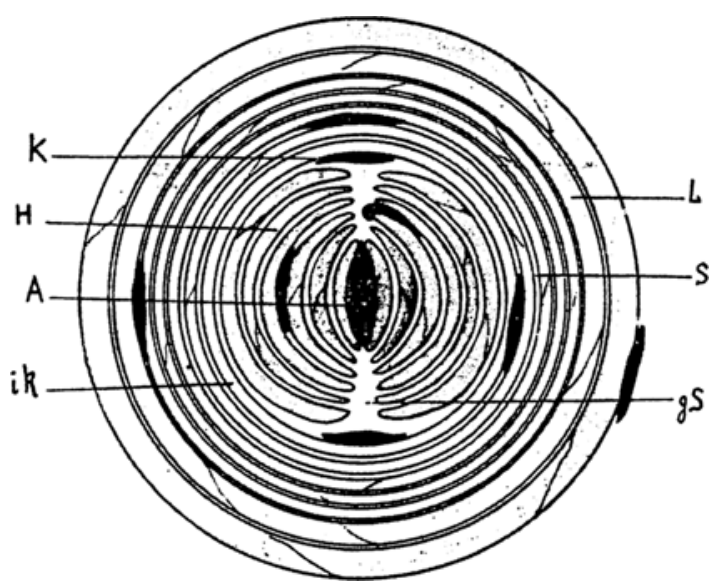

Fig. 1 .

Schema des Innenteiles eines Lamellenkörperchens im Querschnitt. Der abgeflachte Achsenzylinder A wird von sechs Halblamellenpaaren $H$ umfasst, welche in ihrer Gesamtheit den Innenkolben bilden. Die Kanten der Halblamellen schliessen im Vereine mit der innersten kontinuierlichen Lamelle ik den gemeinsamen Spaltraum gS ab. $\mathrm{K}=\mathrm{Kern}$ im gemeinsamen Spaltraum, $\mathrm{L}=$ Lamellenraun. $\mathrm{S}=$ Spaltraum zwischen zwei Lamellen.

übergeben, sondern sie höchstens berühren, meistens aber mit denen der anderen Seite einen kleinen Spaltraum einschliessen. Demnach sind die innersten Lamellen als Halblamellen aufzufassen, die alle in derselben Weise zum Achsenzylinder orientiert sind.

Der Achsenzylinder ist für gewölnnlich mehr oder weniger abgeplattet, so dass er am Querschnitt spindelförmig erscheint. An die Breitseiten des Achsenzylinders lagert sich unmittelbar das innerste Halblamellenpaar an, dieses von aussen umfassend das zweite usf. Indem sich die etwas zugespitzten Enden der Halblamellenpaare gewöhnlich nicht berühren, sondern in einem kleinen Abstande voneinander enden, schliessen sie in ihrer Gesamtheit je einen Spaltraum ein, der in die Verlängerung der Schmalseiten des Achsenzylinders zu liegen kommt. Denkt man sich den Achsenzylinder herausgezogen, so begrenzen beide innersten Halblamellen im Vereine mit den zugespitzten Enden der nach aussen folgenden Halblamellen einen spaltförmigen 
Raum. Der mittlere Teil dieses „gemeinsamen zentralen Spaltraumes" wird vom Achsenzylinder eingenommen, von dem stellenweise Fortsatze weiter peripher in den Spaltraum hineinzuragen scheinen (Raphe Merkels), die möglicherweise den von Retzius $(10,11)$ an Golgi-Prăparaten gesehenen Fortsätzen des Achsenzylinders entsprechen. Nach Retzius strahlen diese Fortsatze vom Nervenfaserstamm und vom Endköpfchen wie kleine knopfförmige Sprossen zu beiden Seiten aus. Ausserdem dürften die beiden bis an die Kanten des zentralen Achsenzylinders heranreichenden Spalträume als Durchtrittspforten für die von mehreren Autoren beschriebenen, vom Achsenzylinder abgehenden Seitenäste bestimmt sein. Erwahnt sei hier noch, dass die unmittelbar an die Schmalseiten des Achsenzylinders sich anschliessenden Teile des gemeinsamen Spaltraumes, gewöhnlich eine feinkörnige Masse enthalten, die vielleicht als Protoplasma der im Spaltraum liegenden Lamellenzellen aufzufassen ist.

Der gemeinsame zentrale Spaltraum halt keine bestimmte Richtung zur Breiten- oder Dickenachse des Körperchens ein, bald fält er mit dem Breitendurchmesser zusammen, bald steht er vertikal oder schräg zu ihm.

Die Lamellenkerne der Halblamellen sind im allgemeinen ebenso gelagert wie die der kontinuierlichen Lamellen; nur wenn ein Kern an der Spitze einer Sichel gelegen ist, erscheint er entweder abgeknickt und förmlich um die Spitze herumgelegt oder er endet im gemeinsamen Spaltraum wie abgebackt, also nicht zugespitzt wie die übrigen Kerndurchschnitte. Häufig findet man auch im gemeinsamen Spaltraum freiliegende Kerne, die am Querschnitte nicht länglich zugespitzt, sondern mebr oder weniger rundlich erscheinen (Fig. 1, K, Taf. VIII). Ich glaube aber, dass es sich auch bei diesen Kernen um Lamellenkerne handelt und nicht um Kerne von Lymphozyten - als Kerne (polymorphkerniger) Leukozyten sind sie schon infolge ihrer Gestalt nicht anzusprechen - die wegen der veränderten Raumbedingungen, die sie an dieser Stelle finden, eine etwas abweichende Form angenommen haben.

Nach aussen von dem Halblamellenkomplex (Innenkolben) schliesst sich stets eine Lage schmaler, dichtgedrängter, kontinuierlicher Lamellen an und erst noch weiter peripher folgen die Lamellen mit ihren breiten Lamellenräumen. 
Die innerste kontinuierliche Lamelle begrenzt mit dem aussersten Halblamellenpaar gewöhnlich einen mehr oder weniger deutlichen Spaltraum, in den sich der gemeinsame Spaltraum beiderseits offnet. Gerade dort, wo der gemeinsame Spaltraum durch die erste kontinuierliche Lamelle abgegrenzt wird, liegt sehr häufig ein Kern (Fig. 2, K, Taf. VIII), so dass man in dieser Lagerung eine gewisse Ähnlichkeit mit der Lagerung der Kerne in zwei Langsreihen bei den Lamellenkörperchen der Vögel erkennen kann.

Als "Innenkolben" oder , inneres Lamellensystem" (Merkel) möchte ich demnach jenen zentralen Teil des Lamellenkörperchens bezeichnen, derzum Unterschiede von den weiter peripher gelegenen Anteilen des Körperchens nicht vonkontinuierlichen, sondern von sechs bis zwölf Paaren von Halblamellen gebildet wird. Die Halblamellenpaare fassen zwischen sich einengemeinsamen Spaltraum, dessen zentraler Anteil vollstandig vom flachgedrückten zentralen Achsenzylinder ausgefült wird.

Die lamellöse Struktur des Innenkolbens ist nicht nur am Querschnitte, sondern auch am Lïngsschnitte zu erkennen (Fig. 9, Taf. VIII), nur kommt natürlich an letzterem die charakteristische Zusammensetzung des Innenkolbens aus Halblamellen nicht zum Ausdruck.

Der Querdurchmesser des Innenkolbens (nach meiner Definition) beträgt im Durchschnitte etwa $35 \mu$, hängt aber von der Gesamtgrösse des Körperchens ab, so dass die Dicke des Innenkolbens nicht unerheblich schwankt, was von allen Autoren hervorgehoben wird.

An seinem distalen Ende enthalt der Innenkolben auffallend viele Kerne, die nicht mehr so regelmässig angeordnet sind wie in seinen übrigen Teilen. Hier kommen auch Kerne vor, die an Leukozytenkerne erinnern, wahrscheinlich aber auch den Lamellenkernen zuzurechnen sind. Auch die Lamellen lassen an dieser Stelle nicht mebr die regelmässige Anordnung erkennen wie in anderen Teilen des Innenkolbens. In einem Falle, in dem der Achsenzylinder an seinem distalen Ende gegabelt war, sah ich jeden der beiden Teiläste von kontinuierlichen Lamellen umgeben, so dass in diesem Falle jede der Halblamellen des Innenkolbens 
in ihrem distalsten Anteile sich $\mathbf{z u}$ einer kontinuierlichen Lamelle geschlossen hat.

Erwăhnt sei noch, dass ich den gemeinsamen zentralen Spaltraum deutlicher an Lamellenkörperchen einer verbluteten als an denen einer mit Kochsalzlösung von der Aorta aus injizierten Katze ausgeprägt fand, was ja begreiflich erscheint, wenn man annimmt, dass durch die Injektion alle Kapselräume stărker gefüllt werden. Die natürliche Folge der stärkeren Füllung der Kapselriume muss eine Einschrankung der Spaltrăume sein.

Wie schon erwähnt, reichen die zugespitzten Enden (am Querschnitte gesehen) der Halblamellen mitunter ganz aneinander heran. In diesen Fällen bekommt man den Eindruck einer Naht, die von den Schmalseiten des Achsenzylinders ausgehend jederseits nahezu bis zur innersten kontinuierlichen Lamelle reicht (Fig. 2, Taf. VIII).

Der Innenkolben mit den dicht gedrăngten unmittelbar nach aussen an ihn sich anschliessenden Kapseln erscheint am gefürbten Prapparat etwas dunkler als die peripheren 'Teile des Lamellenkörperchens und zwar einerseits infolge der dichteren Lagerung der Kapseln, andererseits infolge des etwas stărker farbbaren Kapselinhaltes. Die stärkere Färbbarkeit der Kapselflüssigkeit gegen die Achse des Körperchens hin dürfte auf einen grösseren Eiweissgehalt derselben zurückzuführen sein.

An der Längsachse der Lamellenkörperchen können drei verschiedene Abschnitte unterschieden werden (siehe Schema Textfig. 2). Der erste Abschnitt reicht vom basalen (= proximalen) Pol des Körperchens bis zur Basis der innersten Lamelle und soll als "proximaler Achsenteil ${ }^{*}$ bezeichnet werden. Er wird von den Nerven und von den mit diesen eindringenden Kapillaren eingenommen. In seiner ganzen Ausdehnung nehmen die Lamellen ihren Ausgang.

Der zweite Abschnitt oder ,zentrale Achsenteil ${ }^{*}$ entspricht der Ausdehnung der innersten Lamelle, er wird rom zentralen Achsenzylinder erfülltt.

Der dritte Abschnitt oder "distale Achsenteil ${ }^{\circ}$ erstreckt sich vom distalen Ende des zentralen Achsenzylinders bis zum distalen Pol des Körperchens. In seinem Bereiche liegt, wenigstens annähernd, das Ligamentum interlamellare, wenn ein solches 
vorhanden ist, was übrigens nicht häufig der Fall zu sein scheint; ausserdem können in ihm vom distalen Pole aus eintretende Kapillaren vorkommen.

J

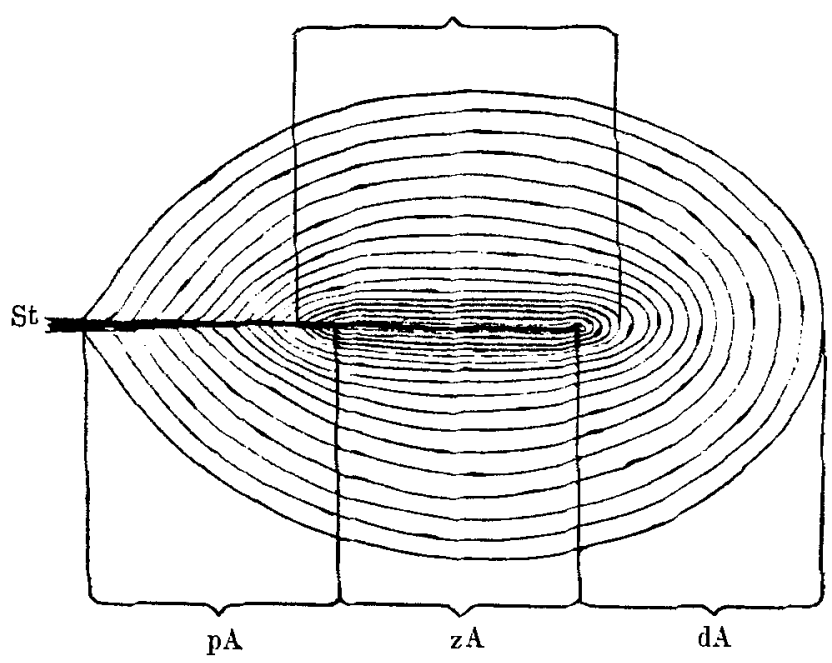

Fig. 2

Schema eines Medianschnittes durch ein Lamellenkörperchen. $\mathrm{pA}=$ proximaler Achsenteil, $\mathbf{z A}=$ zentraler Achsenteil, $\mathrm{dA}=$ distaler Achsenteil. $\mathrm{I}=$ Innenkolben, $\mathrm{St}=$ Stiel des Kürperchens.

Die Längenausdehnung des Innenkolbens fällt nicht genau mit der des zentralen Achsenteiles zusammen, sondern erstere überragt letztere sowohl distal als proximal.

Für den von mir als proximalen Achsenteil benanuten Abschnitt wird von Key und Retzius die Bezeichnung "Stiel“ gebraucht. Ich glaube, dass letztere Bezeichnung nach Analogie an anderen Organen und in Übereinstimmung mit anderen Autoren besser für das ausserhalb des Körperchens gelegene und in dessen basalen Pol eindringende Gefäss- und Nervenbündel veserviert werden soll.

\section{Eigene Untersuchungen über die Blutgefässe der Lamellenkörperchen.}

Die Durchsicht meiner Präparate von Lamellenkörperchen aus der Gegend der Steissbeinspitze des Menschen und im Schwanze langschwänziger Saugetiere ergab, dass auch ohne vorhergegangene Injektion Kapillaren in Lamellenkörperchen leicht nachzuweisen sind. 
So konnte ich in einzelnen Körperchen in der Nähe des Glomus coccygeum eines jungen Weibes ziemlich reichliche Kapillaren eindringen sehen (Fig. 3, Taf. VIII). Die Kapillaren sind hier leicht erkennbar, da alle rote Blutkörperchen enthalten. Es handelt sich um ein Injektionspraparat, wobei die Injektionsmasse zwar nicht in die Kapillaren der Lamellenkörperchen eingedrungen ist, wohl aber das Blut bis dorthin vorgetrieben wurde. Namentlich finden sich gefüllte Kapillaren in den verhältnismässig dicht liegenden äusseren Kapseln der Körperchen. Sie dringen an verschiedenen Stellen von aussen her in die Körperchen ein - keineswegs etwa nur in der Gegend der Pole, wie dies von Michailow beschrieben wurde - und sind an den Reihenschnitten auf ziemlich weite Strecken in ihrem im allgemeinen schrägen Verlaufe durch die Kapseln zu verfolgen.

Ebenso konnte ich bei zwei Neugeborenen an einzelnen Vater-Pacinischen Körperchen die ausseren Kapseln durchsetzende Kapillaren nachweisen, die bis gegen die mittleren Lamellen zu verfolgen sind.

An Querschnitten durch ein Lamellenkörperchen aus dem Schwanze des Iltis sah ich vom basalen Pol mit dem Nerven drei Kapillaren in das Körperchen eindringen, von denen zwei Blutkörperchen enthielten. Die Kapillaren erreichten aber nicht die Basis der innersten Kapsel, also nicht den zentralen Acbsenteil des Körperchens. In Fig. 4, Tat. VIII, habe ich einen Längsschnitt (der etwas seitlich von der Achse des Körperchens geführt ist) durch ein nicht injiziertes Körperchen aus dem Schwanze eines Macacus rhesus abgebildet. Man sieht mebrere Kapillaren in der Gegend des basalen Achsenteiles, Kapillarquerschnitte in der Gegend des distalen Poles in Bindegewebe eingebettet und an verschiedenen anderen Stellen des Körperchens teils längs, teils schräg getroffene Kapillaren.

Bezüglich des Gefäßsystems der zusammengesetzten Lamellenkörperchen in der Nähe des Glomus coccygeum, die, wie schon erwähnt, aus kleineren oder grösseren Gruppen dicht aneinander gedrängter kleiner Einzelkörperchen bestehen und von einer gemeinsamen dicken fibrösen Kapsel umgeben sind, scheint bemerkenswert, dass prikkapillare Gefasse und Kapillaren allenthalben zwischen den einzelnen Körperchen, also innerhalb der gemeinsamen Kapsel, in verhältnismässig grosser Menge zu finden sind, ohne aber in die einzelnen lamellenkörperchen einzudringen. 
Nimmt man all, dass bei erhöhtem Blutdruck aus den Gefasssen innerhalb del zusammengesetzten Lamellenkörperchen eine stärkere Flüssigkeitstranssudation erfolgt, so muss der Turgor im Innern eines derartigen Komplexes von Lamellenkörperchen wesentlich steigen und könnte eventuell als Reiz auf die Nervenendigungen in den Körperchen in der schon oben erwăhnten Art wirken. Es würde bei dieser Annahme auch der Zweck der dichten gemeinsamen Kapsel verständlich; es käme ihr die Aufgabe zu, eine Transsudation aus dem Innern des Lamellenkörperchen-Komplexes in die Umgebung zu verhindern, so dass der Effekt des Flüssigkeitsdruckes auf die einzelnen Körperchen und auf die in diesen sich befindenden Nervenendigungen ein wesentlich höherer sein wird, als wenn keine gemeinsame Kapsel vorhanden wäre. Der gemeinsamen Kapsel dürfte demnach dieselbe Funktion zukommen, wie den ausseren Lamellen der einzeln liegenden grossen Vat e $\mathrm{r}$ - Pac i n i schen Körperchen, vorausgesetzt, dass die Annahme von der Nervenerregung in den Lamellenkörperchen durch stiirkere Transsudation ans den Eigengefässen des Körperchens zutrifft.

Eingehendere Untersuchungen über die Gefasse der Lamellenkörperchen labe ich am Mesenterium der Katze vorgenommen. $\mathrm{Zu}$ diesem Zwecke wurden die Mesenterialgefïsse von der Aorta abdominalis aus mit Berlinerblau bei zwei Katzen injiziert. Bei der ersten Katze gelang die Injektion nicht vollkommen, indem die Eigengefässe der Lamellenkörperchen des Mesenteriums nur in einzelnen Fällen unvollständig gefüllt waren, in anderen gar nicht. Die Ursache des teilweisen Misslingens der Injektion dürfte wohl darin zu suchen sein, dass ich zu kurz nach dem Tode (etwa eine Stunde) die Injektion vornahm. Bei der zweiten Katze injizierte ich erst 24 Stunden nach dem Tode und hier gelang die Injektion gut, so dass nahezu jedes Körperchen injizierte Eigengefässe zeigt. Das ganze Gekröse samt dem Darm wurde in $10 \%$ Formalinlösung gehärtet, dann in Alkohol gebracht, Gekrösestückchen mit Lamellenkörperchen herausgeschnitten, in Xylol aufgehellt und unter dem stereoskopischen Mikroskop untersucht.

Zunächst fallt die bekannte Tatsache auf, dass die Lamellenkörperchen des Mesenteriums hauptsăchlich den grösseren Gefässen angeschlossen liegen. Ja es ist überhaupt kein Körperchen zu 
finden, das nicht mit einem Teile seiner Oberfiache einer wenigstens kleineren Arterie und Vene angelagert wäre; auch die grossen Lymphgefăsse liegen oft unmittelbar an die Obertlăche der Körperchen angeschmiegt (Fig. 5, Taf. VIII). Die Lamellenkörperchen sind im allgemeinen so orientiert, dass ihre Lăngsachse mit der Verlaufsrichtung der Gefässe zusammenfällt. Nur ausnahmsweise liegt ein Körperchen schrüg zu einem grösseren Gefäßstamm. Sehr häufig sitzen Lamellenkörperchen in dem Teilungswinkel der grösseren Gefässe, so dass sie von zwei Seiten von Gefässen umfangen werden. Oft zweigt von den grösseren Gefässen, denen ein Körperchen aufliegt, ein Ast (von der Arterie oder Vene oder von beiden) ab, umschlingt bogenförmig den distalen Pol des Körperchens, sich innig an seine Oberf'äiche anlegend, oder aber es zieht ein Gefassast quer bogenförmig über das Körperchen, wie dies schon Herbst erwähnte. In manchen Fällen schliessen die grösseren Gefásse im Vereine mit den von ihnen ausgehenden feineren $\ddot{A}$ sten und Präkapillaren einen förmlichen Gefässkranz um die grösste Peripherie des Körperchens ab.

Die Anlagerung der grösseren Gefusse an die Lamellenkörperchen ist eine so innige, dass man an Schnittpritparaten bei stark gefüllten Gefässen die Körperchen im Bereiche der Anlagerungsstelle der Gefässe häufig eingedrückt findet. Dieser Umstand spricht, wie schon oben angedeutet, dafür, dass die innige Lagebeziehung der Körperchen zu den Gefassen funktionell nicht bedeutungslos sein dürtte. Bei stärkerer Füllung müssen die anliegenden Gefässe einen starkeren Druck auf die Obertlache der Körperchen ausüben, der auf das Innere derselben übertragen, als Reiz auf die Nervenendigungen wirken könnte. In ahnlicher Weise stellt sich Thoma, wie schon hervorgehoben, eine direkte Einwirkung des Gefässtonus auf die Lamellenkörperchen vor.

Bezüglich der in die Körperchen eindringenden Gefässe ist am aufgehellten Präparat zu erkennen, dass diese nicht als direkte Zweige von Arterien oder Venen abgehen, sondern dass sich noch ausserhalb des Körperchens in der Nahe seines basalen Poles ein Kapillarnetz bildet, in das sich sowohl Arterien- als auch Venenaste auflösen (Fig. 7, Taf. VIII). Nebenbei bemerkt sei hier, dass ich in der Nähe dieses ausserhalb des Körperchens gelegenen Geflechtes in einem Falle (Fig. 7, An) zwei direkte Verbindungen zwischen einem Arterien- und Venenstamm (arterio-venöse Ana- 
stomosen) nachweisen konnte. Von dem erwabunten Kapillarnetz dringen gewöhnlich mehrere Äste mit den Nerven oder auch in ihrer Nähe in die Basis des Körperchens ein und bilden bier abermals ein Kapillarnetz mit mehr oder weniger reichlichen Schlingen. Von diesem Netz entspringt eine Kapillarschlinge (Fig. 7 und 9 , Taf. VIII), die weiter distal in der Achse des Körperchens vordringt, mit ihrem Scheitel aber höchstens den Boden der innersten Lamelle erreicht, also bis zur distalen Grenze des proximalen Achsenteiles vordringt, wie dies schon zutreffend von $\mathrm{Herbst}$ (3) beschrieben wurde. Diese Kapillarschlinge scheint in jedem Körperchen vorlaanden $\mathrm{zu}$ sein und zeichnet sich durch etwas weiteres Kalibel als die feinsten, z. B. in dem die Körperchen umgebenden Fettgewebe gelegenen Kapillaren, aus. Bedeutend seltener dringen Kapillaren an anderen Stellen in die Körperchen ein. Allerdings fallt hier die Entscheidung, ob die Kapillaren die oberfanchlichen Lamellen durchsetzen oder nur an der Oberfliche des Körperchens liegen, nicht leicht. Nur in einem Falle sah ich mit Bestimmtheit am anfgehellten Priparat eine Kapillare am distalen l'ol des Kürperchens eintreten, die eine Schlinge bildete, deren Scheitel bis zum distalen Ende des zentralen Achsenteiles vordrang. Niemals konnte ich, im Gegensatz zu Michailow, ein Kapillarnetz im Bereiche des ganzen Innenkolbens finden; stets entbehrte der zentrale Achsenteil der Kapillaren. Möglicherweise ist das Verhalten der Gefisse in den Lamellenkörperchen verschiedener Körpergegenden ein etwas verschiedenes.

An Schnitten durch injizierte Körperchen konnte das geschilderte Verhalten der Gefusse im Imnern der Lamellenkörperchen bestätigt werden, so dass dem oben gesagten nicht viel hinzuzufügen bleibt. Im basalen Anteil der Körperchen findet man stets nicht nur axial, sondern an verschiedenen Stellen, oft auch nahe der Oberflache des Körperchens, Kapillaren zwischen den Lamellen (Fig. 9, Taf. VIII); auch im distalen Abschnitt der Körperchen sind Kapillaren nachzuweisen, die keineswegs nur axial verlaufen. Stets bleibt aber der Innenkolben in seinem Hauptabschnit, der der Ausdehnung des zentralen Achsenteiles entspricht, vollkommen gefässfrei. Wenn auch die Injektion unvollkommen sein sollte, so müssten im Bereiche des Innenkolbens wenigstens die 
Durchschnitte leerer Kapillaren nachzuweisen sein, was aber in keinem Falle möglich war. Erwabnenswert scheint mir noch, dass man manchesmal an einem basal in ein Körperchen eindringenden Gefäss circuläre Muskelfasern nachweisen kann, so dass demnach nicht ausschliesslich Kapillaren, sondern wenigstens mitunter auch kleinste Arterien in das Körperchen eintreten.

\section{Experimentelle Untersuchungen.}

Von den sehr spärlichen bisher angestellten Versuchen die Frage der Funktion der Lamellenkörperchen experimentell za lösen, will ich hier die von $\mathrm{R}$ a uber (9) erwähnen. Nach Ra uber sind die Vaterschen Körperchen selbst für sehr geringen Druck äusserst empfindlich. Bedeckt man die Körperchen mit Gläschen im Gewicht von $2 \mathrm{mg}$ bis $1 \mathrm{~g}$, so nimmt bei Mensch und Katze ihr Längendurchmesser beiläufig um $1 / 8$, ihr Breitendurchmesser um 1/4, beim Hahn Längen- und Breitendurchmesser um 1/10 $\mathrm{zu}$. An dieser Zunahme des Lilngen- und Breitendurchmessers beteiligen sich in von aussen nach innen abnehmender Starke die verschiedenen Kapseln. „Schon bei geringem Drucke, kleinerem, als man von vornherein annehmen sollte, wurde das Maximum der Ausdebnung erreicht. Nur selten wirkte eine Belastung von über $1 \mathrm{~g}$ noch ausdehnend, sei das diesem nahe Gewicht in allmählicher Steigerung oder sogleich aufgelegt worden. Dagegen zeigte sich meist, dass nach der Entfernung einer Last von $50 \mathrm{mg}$ das Körperchen seine frühere Gestalt verloren hatte, abgeplattet, verzogen, vernichtet war."

Ausgehend von der Vorstellung, dass auf eine starkere Durchfeuchtung des umgebenden Gewebes die Lamellenkörperchen mit einer Aufquellung reagieren dürften, unternabm ich schon seinerzeit, bald nach dem Erscheinen meiner Arbeit über das Glomus coccygeum und die Glomeruli caudales, worin ich meine Ansicht über die Funktion der Lamellenkörperchen auseinandergesetzt hatte, diesbezügliche Versuche.

Von drei jungen Katzen wurden Stïcke des Mesenteriums, welche Vater-Pacinische Körperchen enthielten, auf einen Korkrahmen unter möglichster Vermeidung von Zerrungen mit Nadeln aufgespannt und zunächst ohne jeden Zusatz (und ohne Deckglas) unter dem Mikroskop mittels eines Okularmikrometers 
gemessen. ${ }^{1}$ ) Hierauf wurde ein Tropfen physiologischer, auf Körpertemperatur erwârmter Kochsalzlösung auf das beobachtete Lamellenkörperchen gebracht, ohne dessen Lage zu verăndern und abermals gemessen. Hierbei stellte sich sofort nach der Befeuchtung oder nur kurze Zeit (wenige Sekunden) nachher eine Formveränderung am Lamellenkörperchen ein und zwar im gegenteiligen Sinne als erwartet worden war, indem nämlich in der Regel eine Verkürzung sowohl des Längen- wie des Breitendurchmessers des Körperchens eintrat. In einigen Fällen konnte nicht mit voller Bestimmtheit die Langenabnalıme der beiden Durchmesser nachgewiesen, sicher aber eine Längenzunahme derselben ausgeschlossen werden. Die Messungen wurden allerdings wesentlich durch das die Körperchen umgebende Fettgewebe erschwert. Nach der Befeuchtung scheint das Gewebe über die Ränder des Körperchens gegen dessen Mitte etwas vorzurücken, wodurch die Umrisse des Körperchens verschleiert werden und eine scharfe Einstellung auf dieselben erschwert wird.

Zunächst dachte ich daran, dass die Längenabnahme der beiden Durchmesser eine Folge der Konzentration oder der Temperatur der Kochsalzlösung sein könnte und versuchte deshalb mit stärkeren und sclwächeren Kochsalzlösungen, dann mit wärmeren und kälteren Lösungen, aber immer mit demselben Erfolge. Stets konnte eine Längenzunahme der beiden Durchmesser ausgeschlossen, hingegen eine Längenabnahme derselben mit ziemlich grosser Sicherheit nachgewiesen werden. Ich habe seinerzeit die Veröffentlichung dieser Versuche unterlassen, da ich mir die Erscheinungen nicht erklären konnte und ich mir dachte, dass vielleicht doch Beobachtungsfehler, bedingt durch die erwähnten Verschiebungen des Fettgewebes in der Umgebung der Körperchen, vorliegen könnten.

Angeregt durch die Arbeit Michailows nahm ich abermals die Versuche auf und zwar in einer etwas anderen Anordnung. Ich suchte nämlich durch erhöhten Druck in den Mesenterialgefässen die Form der Lamellenkörperchen $\mathrm{zu}$ beeinflussen. $\mathrm{Zu}$ diesem $Z$ wecke wurde folgendermassen vorgegangen:

1) Selbstverständlich wurde diese Prozedur möglichst rasch und unmittelbar nach dem Tode der Katze vorgenommen, so dass das beobachtete Mesenteriumstück noch nicht ausgetrocknet war. 
Eine Katze wurde in Narkose durch Durchschneiden der Carotiden verbluten gelassen, dann die Brust- und Bauchhöhle erötfnet und eine Kanüle in die Aorta descendens vor dem Abgange der A. mesenterica superior eingebunden. Hierauf wurde ein Stuick des Mesenteriums, in welchem ein Lamellenkörperchen möglichst frei lag, unter dem Mikroskope auf einen Korkrahmen mit Nadeln fixiert und die Länge und Breite des beobachteten Körperchens gemessen. Nachdem dies geschehen war, injizierte der Assistent bei mässigem Drucke physiologische, auf Körpertemperatur erwärmte Kochsalzlösung, wälırend ich unter dem Mikroskope das vorlier gemessene Lamellenkörperchen beobachtete. Wïhrend der Injektion sieht man, dass das Körperchen eine Formveränderung eingeht, die auf den ersten Blick nicht leicht zu definieren ist. Die Umrisse des Körperchens werden unschärfer, man muss auf ein anderes Niveau mit der Mikrometerschraube einstellen, um die Konturen wieder deutlich zu seben und die Durchmesser genau messen zu können. Die Messung nach der Injektion ergab wieder, sowie nach der Befeuchtung eines Lamellenkörperchens am herausgeschnittenen Gekrösestück, eine Verkürzung des Lüngen- sowie des Breitendurchmesser's des Körperchens.

So betrug in dem ersten diesbezüglichen Versuch:

die Länge des Lamellenkörperchens vor der Injektion $1152 \mu$;

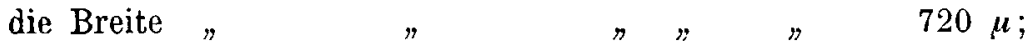
die Länge \# $\# \quad$ nach $\# \quad$ $\quad 992 \mu$; die Breite " $" \quad " \quad n \quad 688 \mu$.

Nach diesem Versuche wurden die Baucheingeweide samt der Aorta abdominalis herausgenommen, die A. coeliaca und die Aorta kaudal vom Abgange der A. mesenterica superior unterbunden, wieder ein Teil des Mesenteriums mit einem Lamellenkörperchen unter das Mikroskop gebracht und gemessen. Hierbei blieb die Kanüle in die Aorta abdominalis eingebunden und nun wurde nach der Messung des eingestellten Lamellen körperchens neuerdings physiologische Kochsalzlösung injiziert und nach der Injektion abermals gemessen. Hierbei ergaben sich folgende Maße :

Länge des Körperchens vor der Injektion . 92S $\mu$;

Breite $" n \quad n \quad \# \quad$. $560 \mu$;

Länge $" \quad$ nach $" \quad n \quad 800 \mu$;

Breite $n \quad n \quad n \quad$ n $\quad 528 \mu$; 
Dieser Versuch wurde bei einer zweiten Katze wiederholt, nur wurden hier schon gleich anfangs die Baucheingeweide samt der Aorta abdominalis herausgenommen und von letzterer aus (kranial vom Abgange der A. mesenterica superior nach Unterbindung der A. coeliaca und des kaudalen Abschnittes der Aorta abdominalis) physiologische Kochsalzlösung injiziert. Ein vor und nach der Injektion gemessenes Lamellenkörperchen zeigte dieselben Veränderungen wie in den früheren Füllen; das heisst nach der Injektion - nachdem in diesem Falle allerdings auch auf die Oberflilche des beobachteten Gekrösestückchens physiologische Kochsalzlösung gebracht worden war - erschien der Lüngen- wie der Breitendurchmesser verkürzt:

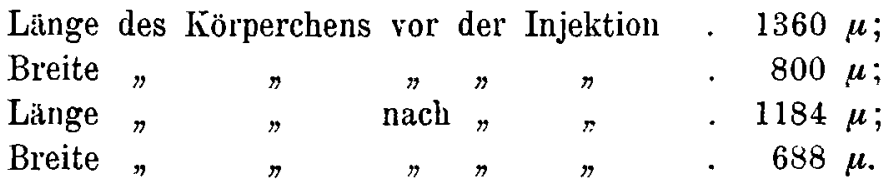

Hierauf wurde ein Gekrösestück mit einem anderen Lamellenkörperchen herausgeschnitten, eingestellt und gemessen, dann mit physiologischer Kochsalzlösung befeuchtet und abermals gemessen:

Länge des Körperchens vor der Befeuchtung $1200 \mu$;

\begin{tabular}{|c|c|c|c|c|c|}
\hline Breite & " & & & $n$ & $768 \mu$ \\
\hline Lange $n$ & $n$ & nach & 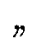 & $\pi$ & $1168 \mu ;$ \\
\hline Breite & " & $\eta$ & 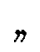 & n & $720 \mu$. \\
\hline
\end{tabular}

Weiterhin wurde ein Lamellenkörperchen vollkommen aus seiner Umgebung herauspripariert, was unter Zubilfenahme einer Lupe nicht schwer gelingt. Man spaltet zu diesem Zwecke die Tunica serosa mit einer spitzen Lanzette, worauf sich das Lamellenkörperchen aus dem Fettgewebe der Lamina mesenterii propria herausschälen lassst, so dass es vollständig frei, ohne anlagerndes Fettgewebe, unter dem Mikroskop beobachtet werden kann. Nun wurde das isolierte Körperchen zunächst auf einen Objektträger gebracht und ohne Zusatz (und obne Deckgläschen) gemessen, hierauf wurde ein Tropfen physiologischer Kochsalzlösung zugesetzt, so dass das Körperchen allseitig von Flüssigkeit umgeben war und abermals gemessen:

Länge des Körperchens vor dem Flüssigkeitszusatz . $1200 \mu$;

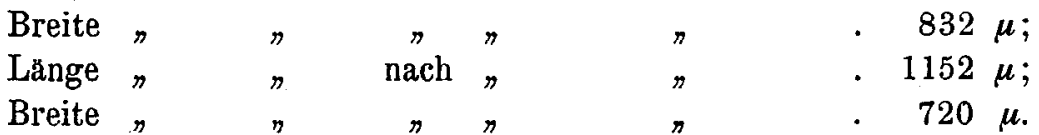


Noch später, etwa 21/2 Stunden nach dem Tode der Katze, wurden noch zwei weitere Körperchen isoliert, gemessen und befeuchtet. In diesen beiden Făllen konnte aber keine Verkürzung der beiden Durchmesser der Körperchen nach der Befeuchtung mehr nachgewiesen werden, eher erschienen nach dem Kochsalzlösungzusatz die Durchmesser etwas vergrössert.

Ein weiterer Versuch mit Injektion von physiologischer Kochsalzlösung durch die A. mesenterica superior bei einer dritten (alten) Katze ergab verhältnismässig geringfügige Änderungen in den Dimensionen eines beobachteten Körperchens:

Länge des Körperchens vor der Injektion . . $992 \mu$;

Breite \# $\# \quad \# \quad \# \quad$. . $640 \mu$;

Länge $" \quad$ nach $\# \quad \eta \quad . \quad 960 \mu$;

Breite $" \#, \quad n$. $\quad 624 \mu$.

Bei einer vierten und letzten (jungen) Katze ergab die Messung eines Körperchens vor und nach der Injektion von physiologischer Kochsalzlösung durch die Aorta abdominalis:

Lange des Körperchens vor der Injektion . $1120 \mu$;

Breite " $\quad$ " $\quad$. $560 \mu$;

Lange " $"$ nach $" ~ \# \quad 1040 \mu$;

Breite $" \# \quad " \quad \Rightarrow \quad 512 \mu$;

Die aus den mitgeteilten Versuchen sich ergebende, auf den ersten Blick überraschende und unerwartete Tatsache der Abnahme des Längen- und Breitendurchmessers der Lamellenkörperchen sowohl bei grösserem Druck in den Gefässen als auch bei stärkerer Durchfeuchtung des umgebenden Gewebes würde sich. leicht erklaren lassen, wenn nachgewiesen werden kann, dass die Lamellenkörperchen bei verhältnismässig geringem Blutdruck, resp. schwacher Durchfeuchtung des anliegenden Gewebes keine Eiform besitzen, sondern abgeplattet sind, so dass also ihr Querschnitt nicht kreisförmig, sondern elliptisch wăre.

Wir können die drei Dimensionen eines Lamellenkörperchens als Lange, Breite und Dicke bezeichnen. Die Lănge und Breite würden parallel zur Obertlăche des Gekröses liegen, die Dicke senkrecht darauf, wobei also nachzuweisen wäre, dass die Breite im allgemeinen grösser ist als die Dicke. Würden nun, beim Zutreffen dieser Annahme, die Körperchen bei stärkerer Durchfeuchtung aufgeblăht, so würde die năchste Folge die sein, dass die Körperchen, von der Fläche betrachtet, kürzer und schmäler er- 
scheinen werden, wobei natürlich ihr Dickendurchmesser zunehmen würde. Sind die ăussersten Lamellen der Körperchen nicht oder nur sehr wenig dehnbar, so könnte die Aufblahhung nur so weit gehen, bis die Dicke gleich gross wie die Breite des Körperchens geworden ist, so dass das Körperchen am Querschnitt kreisförmig und nicht mehr elliptiseh wie im kollabierten Zustande erscheinen würde.

So zahlreiche Maßangaben über die an verschiedenen örtlichkeiten vorkommenden Vater-Pacinischen Körperchen, namentlich in der älteren Literatur, auch vorliegen, so beschränken sich diese nahezu ausnahmslos nur auf zwei Dimensionen, namlich auf die Lange und Breite der Körperchen. Nur R a uber (9) spricht ausser von einer Lange und Breite auch von einer Dicke der Körperchen, ohne aber im allgemeinen für letztere gesonderte Zahlen anzugeben. Nur von den Lamellenkörperchen in den Gelenkkapseln des Hahnes bemerkt $\mathrm{R}$ a u ber, "dass ihr Dickendurchmesser etwas unter den Breitendurchmesser zurücksinkt".

In der Erwartung, die an frischen Lamellenkörperchen durch verschiedene Füllung der Gefiusse resp. verschieden starke Durchfeuchtung des umgebenden Gewebes erzeugten Formveränderungen auch am konservierten Material nachweisen zu können, liess ich eine Katze verbluten, whrend einer zweiten gleichgrossen Katze, ohne sie vorher verbluten zu lassen, unmittelbar nach dem Narkosetode in die Aorta descendens ein grösseres Quantum auf Körpertemperatur erwarmter physiologischer Kochsalzlösung injiziert wurde. Die Baucheingeweide beider Katzen wurden in das. gleichgrosse Quantum 10\% Formalin eingelegt und nach einwöchentlicher Hårtung wurde von beiden Katzen aus dem Gekröse eine grössere Anzahl von Stückchen mit Vater-Pacinischen Körperchen herausgeschnitten. Hierbei wurde die Schnittrichtung so gewählt, dass später eine Orientierung der Körperchen nach ihrer Längsachse möglich war. Die auf diese Weise gewonnenen Präparate wurden in genau gleicher Art weiterbehandelt, in Celloidin eingebettet und in Schnittreihen zerlegt. Die Schnittrichtung wurde so gewählt, dass die Körperchen möglichst genau quer getroffen waren.

Es war zu erwarten, dass die Körperchen der verbluteten Katze eine grössere Differenz zwischen Breiten- und Dickendurchmesser zeigen würden als die der injizierten Katze, vorausgesetzt, dass die Formen in ihrem natürlichen Zustande fixiert worden waren. 
Leider war diesbezüglich das Ergebnis kein ganz einwandfreies, indem alle Lamellenkörperchen, sowohl von der injizierten als auch der verbluteten Katze, an ihrer Oberfläche stellenweise Schrumpfungen zeigten und zwar in der Richtung der Längsachse der Körperchen. Auch ein Fixierungsversuch in Formol-Alkohol ergab keine besseren Resultate. Wenn daher auch die Einzelmaße nicht in jedem Falle genau mit den Maßen der Körperchen im frischen Zustande übereinstimmen werden, so dürften doch die Durchschnittsmaße einen annähernd richtigen Ausdruck der Formverhältnisse der Körperchen geben. Von den Körperchen der verbluteten und der injizierten Katze wurden je zehn gemessen und zwar wurde in der Serie einer der Schnitte hierzu gewählt, der annähernd durch die Mitte des Körperchens geht. Ausdrücklich sei hervorgehoben, dass unter den $\mathrm{zu}$ messenden Körperchen keinerlei Auswahl getroffen, sondern die ersten zehn geschnittenen Körperchen beider Katzen gemessen wurden. In beistehender Tabelle führe ich die absoluten Breiten- und Dickenmaße der Körperchen der verbluteten und injizierten Katze und die daraus sich ergebenden Durchschnittsmaße an. Bemerkt sei hier noch, dass nahezu ausnahmslos der kleinere Durchmesser des Körperchenquerschnittes, also die Dicke, senkrecht auf die Fläche des Gekröses zu stehen kommt, während der grössere Durchmesser, die Breite, in der Fläche des Gekröses liegt. Nur in der unmittelbaren Nachbarschaft der grossen Gefüsse, wo die Lamina mesenterii propria reichliches Fettgewebe führt, kommen Ausnahmen von dieser Regel vor.

\begin{tabular}{c|c|c||c|c|c}
\hline \multicolumn{3}{c||}{ Injizierte } & \multicolumn{3}{c|}{ Katzerblutete Katze } \\
\hline Nr. & Breite in $\mu$ & Dicke in $\mu$ & Nr. & Breite in $\mu$ & Dicke in $\mu$ \\
\hline 1 & 560 & 560 & 1 & 512 & 384 \\
2 & 464 & 432 & 2 & 448 & 400 \\
3 & 544 & 512 & 3 & 560 & 304 \\
4 & 576 & 512 & 4 & 512 & 448 \\
5 & 544 & 544 & 5 & 560 & 368 \\
6 & 576 & 512 & 6 & 464 & 384 \\
7 & 688 & 640 & 7 & 592 & 416 \\
8 & 544 & 368 & 8 & 464 & 320 \\
9 & 480 & 480 & 9 & 512 & 512 \\
10 & 544 & 464 & 10 & 560 & 400 \\
Durch- & 552 & 502.4 & Durch- & 518.4 & 393.6 \\
schnitt & & & & &
\end{tabular}


Aus den vorstehenden Zahlen ergibt sich zunachst, wie ja zu erwarten war, dass der Querschnitt der Lamellenkörperchen der injizierten Katze von der Kreisform weniger abweicht als der der verbluteten Katze, indem sich bei ersterem im Durchschnitt die Breite zur Dicke verhall wie 552:502,4, bei letzterem wie $518,4: 393,6$. Setzt man in beiden Fallen die Breite $=1$, so ergibt sich für die Körperchen der injizierten Katze eine Dicke von 0,910 , für die der verbluteten von 0,759 . In Textfig. 3 habe ich dieses Verhältnis bildlich ausgedrückt.
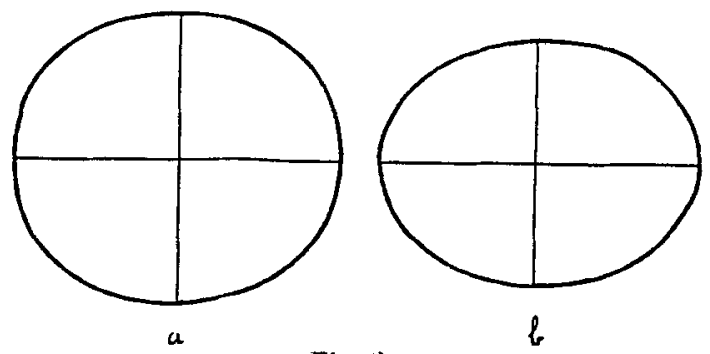

Fig. 3.

Durchschnittliche Umrisse des Querschnittes von Lamellenkörperchen; a nach Kochsalzinjektion in die Gefässe, b nach Verblutung.

Bei ein und demselben Körperchen müsste bei der Zunahme des Dickendurchmessers eine entsprechende Abnahme des Breitendurchmessers eintreten; man würde demnach bei der injizierten Katze einen im Durchschnitt kleineren Breitendurchmesser erwarten als bei der verbluteten Katze. Dass der gefundene Durchschnittswert für den Breitendurchmesser bei der injizierten Katze grösser ist als bei der verbluteten, dürfte sich einerseits durch die verschiedene Grösse der Lamellenkörperchen bei ein und derselben Katze erklären lassen - es könnten ja zufällig bei der injizierten Katze verhältnismässig breite Körperchen zur Messung gelangt sein - andererseits durch die längst bekannte Tatsache, dass bei verschiedenen Katzen die Lamellenkörperchen in hohem Grade verschiedene Durchschnittsdimensionen aufweisen, so dass in diesem Falle die injizierte Katze durch Lamellenkörperchen grösserer Dimensionen gegenüber der verbluteten ausgezeichnet gewesen sein könnte.

Bei Betrachtung der einzelnen Werte der Körperchendimensionen beider Katzen findet man, dass bei der injizierten 
Katze drei von zehn Körperchen genau gleichbreit und gleichdick erscheinen, während dies bei der verbluteten Katze nur für eins von zehn Körperchen zutrifft. Die grössten Differenzen zwischen Breite und Dicke zeigt das Körperchen Nr. 3 der verbluteten Katze mit $560 \mu$ Breite und $304 \mu$ Dicke, bei der injizierten Katze Nr. 8 mit $544 \mu$ Breite und $368 \mu$ Dicke. Demnach erreicht keines von den Körperchen der injizierten Katze, in bezug auf die Grösse der Differenz zwischen Breiten- und Dickendurchmesser, das am meisten abgeflachte Körperchen der verbluteten Katze. Es kann somit ein Körperchen derart aufgeblaht werden, dass es am Querschnitt kreisförmig erscheint, wăhrend andererseits ein Körperchen so weit kollabieren kann, dass sein Dickendurchmesser nicht viel mehr als die Halfte des Breitendurchmessers beträgt (Dicke:Breite $=304: 560$ ), wobei nicht gesagt sein soll, dass nicht noch eine grössere Differenz zwischen Dicken- und Breitendurchmesser erreicht werden könnte. In Textfig. 4 sind diese beiden Grenzfalle bildlich dargestellt.

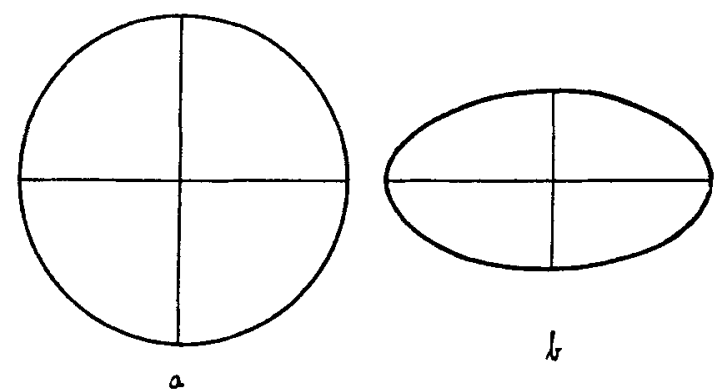

Fig. 4.

Querschnittsumarisse, a eines maximal aufgeblähten Lamellenkörperchens nach Kochsalzinjektion in die Gefässe, b eines maximal kollabierten Körperchens nach Verblutung.

Jedenfalls ergibt sich aus dem angeführten Verhältnis des Dicken- zum Breitendurchmesser, dass im allgemeinen die beiden Querdurchmesser nicht gleichgross sind, dass also nahezu alle Körperchen in der Richtung der Flächenausdehnung des Gekröses abgeflacht erscheinen und dass nur bei extremer Füllung der Lamellenrame ihre Querdurchmessergleichgross werden können. Würde man ein Körperchen auf seine Schmalseite (Kante) eingestellt haben und nun durch Injektion den 
Druck in den Gefässen erhöhen, so wăre zu erwarten, dass bei der Injektion der Querdurchmesser zunehmen und der Längsdurchmesser abnehmen würde. Da aber, wie schon gesagt, die Körperchen im allgemeinen so orientiert sind, dass ihre Breite (d. i. der grössere Querdurchmesser) mit der Flăche des Gekröses zusammenfallt und nur dort, wo die Lamina mesenterii propria durch reichliches Fettgewebe ausgezeichnet ist, d. i. an Stellen, wo überhaupt im frischen Zustande eine Messung der Körperchen infolge der beträchtlichen Dicke des Gekröses ausgeschlossen erscheint, die Körperchen auch anders eingestellt sein können, erklärt es sich, dass in allen beobachteten Fallen eine Abnahme des queren Durchmessers nach der Injektion resp. nach der Befeuchtung der Körperchen eingetreten ist.

Dass die Lamellenkörperchen in der Regel nicht walzenförmig, sondern abgeflacht sind, lissst sich ohne weiteres an isolierten Körperchen sowohl im frischen als auch im fixierten Zustande unter dem stereoskopischen Mikroskope nachweisen. ${ }^{1}$ )

Wurde schon durch die Belastungsversuche von $\mathrm{Rauber}$ gezeigt, dass die Lamellenkörperchen durch geringen auf ihre Oberfläche wirkenden Druck ihre Gestalt verändern, so ergaben meine Versuche, dass ebenso eine Formverilnderung der Körperchen eintritt bei stïrkerer Füllung ihrer Lamellenriume, bedingt durch stärkeren Druck in den Eigengefüssen des Körperchens und, wie es scheint, auch durch stärkere Durchfeuchtung des umgebenden tewebes, wobei es wahrscheinlich zu einer Diffusion von der Umgebung in die Lamellenräume kommt. Wir haben uns vorzustellen, dass bei massigem Blutdruck und daher auch bei mäsiger Durchfeuchtung des Gewebes die Körperchen in mäsigem Grade kolla-

1) Bemerkt sei hier noch, dass nach der Kochsalzinjektion das Mesenterium bedeutend dicker erscheint als nach der Verblutung; die Lamina mesenterii propria ist aufgequollen. Man könnte vielleicht daran denken, dass diese Aufquellung des Mesenteriums die Ursache für die Formveränderung der Lamellenkörperchen ist, so dass diese durch die unmittelbare Anlagerung der beiden Tunicae serosae abgeflacht werden und sobald durch Aufquellung der Lamina propria mehr Raum für die Lamellenkörperchen geschaffen wird, diese, ihrer Elastizität folgend, sich mehr der Kugelform nähern. Gegen diese Auffassung spricht aber die Tatsache, dass auch vollständig isolierte Körperchen für gewöhnlich abgeflacht erscheinen und erst nach Befeuchtung walzenförmig werden. 
biert sind, whrend sie bei wachsendem BIutdruck so weit aufgeblaht werden, als es die oberflachlichsten Lamellen gestatten. Dass es hierbei nicht $\mathrm{zu}$ einer Vergrösserung der Oberfläche der Körperchen kommt, dass also die Körperchen bei höherem Blutdruck nicht in allen ihren Dimensionen zunehmen, muss auf einer geringen Ausdehnungsfăhigkeit der Lamellenwände berulsen. Veranderungsfahig ist nur das Volumen, nicht aber die Grösseder Oberfläche. Geht ein Körperchen aus dem kollabierten in den aufgebläbten Zustand über, so muss entsprecbend der Dickenzunahme die Breite und a uch die Lange abnehmen; es muss sich das Körperchen mehr oder weniger der Kugelform nahern.

Bei starker Füllung der Lamellenraume mit Flüssigkeit muss ein Druck auf die Nervenendigungen im Innern des Körperchens ausgeübt werden. Dieser Druck wird allerdings so lange schwach sein, als das Körperchen noch abgeflacht ist, sobald es aber Walzenform angenommen hat und sich nicht mehr weiter aufblähen kann, wird die Druckwirkung auf die Nervenendigungen im Innern des Körperchens voll zur Geltung gelangen. Da der Innenkolben, sowie das ganze übrige Körperchen aus mit Flüssigkeit gefüllten Lamellen aufgebaut wird, so erscheint er sehr gut geeignet, einen Druck auf den Achsenzylinder zu übertragen.

Es ist anzunehmen, dass die Nervenendigungen im Körperchen durch den auf sie ausgeübten Druck erregt werden, dass diese Erregung zentripetal weitergeleitet und auf die Vasomotoren übertragen wird, so dass in dem Gefässgebiete, wo das stark gefüllte Körperchen, von dem die Erregung ausging, gelegen ist, der Blutdruck sinkt. Bei steigendem Blutdruck in einem Gefăssgebiete, das Lamellenkörperchen enthält, muss auch der Druck in den reichlichen Eigengefässen der Körperchen zunehmen und die unmittelbare Folge wird eine stärkere 'Transsudation aus den Binnengefässen des Körperchens in die Lamellenräume hinein sein, letztere werden stärker gefüllt, der Binnendruck des Körperchens steigt, die Nervenendigungen im Körperchen werden erregt.

Die Versuche lassen vermuten, dass auch eine starkere Durchfeuchtung des Gewebes in der Umgebung der Körperchen, 
wie eine solche bei höherem Blutdruck eintreten muss, aufquellend auf die Körperchen einwirkt. Es dürfte von aussen her in das Körperchen hinein Flüssigkeit diffundieren, vorausgesetzt, dass im Innern der Körperchen ein kleinerer Flüssigkeitsdruck herrscht als in der Umgebung. Wenigstens wird ein grosser Flüssigkeitsgehalt des umgebenden Gewebes bei steigendem Druck im Körperchen eine Diffusion aus dem Körperchen in die Umgebung bis zu einem gewissen Grade verhindern und so einer Abnahme der Blähung des Körperchens entgegenwirken.

Ausserdem dürfte auch der innigen Lagebeziehung der Lamellenkörperchen zu grösseren Gefässen, wie man sie an vielen Örtlichkeiten findet, eine funktionelle Bedeutung zukommen und zwar in der Art, dass, wie dies schon Thoma (14) ausgesprochen hat, stark gefüllte Gefässe einen Druck auf die Oberfläche der Körperchen ausüben, der auf die Nervenendigungen übertragen werden könnte and zwar um so wirksamer, je stirrker die Körperchen mit Flüssigkeit gefüllt sind.

So dürften alle drei Momente, nämlich starke Füllung der Binnengef asse des Körperchens, hochgradige Durchfeuchtung des umgebenden Gewebes und starke Füllung der dem Körperchen oberflachlich angelagerten Gefässe gleichzeitig zusammenwirken können, um den Druckeffekt a f die Nervenendigungen im Körperchen zu erhöhen.

Weiterhin spricht, wie schon früher hervorgehoben, die Lokalisation für die Auffassung der Lamellenkörperchen als Blutdruckregulatoren: Das oft massenhafte Vorkommen derselben in der Nähe der arterio-venösen Anastomosen (in den Endphalangen der Fledermäuse, in der Gegend des Glomus coccygeum beim Menschen, im Schwanze der langschwänzigen Säugetiere), die wohl allgemein als blutdruckregulatorische Apparate aufgefasst werden; die Lagerung in der Adventitia (oder deren unmittelbaren Nachbarschaft), der Aorta und ihrer grösseren Äste (Thoma); das reichliche Vorhandensein in serösen Häuten (Mesenterium der Katze) und in den Gelenkskapseln, wo ja eine Feuchtigkeitsregulation von grösster Bedeutung ist. Auch das Vorkommen der Körperchen an den Fingern, speziell an den Endgliedern, das wohl zunăchst die Ursache war, die Körperchen als Drucksinnesorgane aufzufassen, spricht eher für als gegen die Auffassung, 
dass die Lamellenkörperchen Blutdruckregulatoren sind. Gerade hier ist ja eine prompte Wärmeregulation nötig und diese geht Hand in Hand mit der Blutdruckregulation.

Freilich muss die hier entwickelte Auffassung der Lamellenkörperchen als Blutdruckregulatoren vor der Hand noch Hypothese bleiben, aber wie mir scheint, eine besser begründete als die, welche den Lamellenkörperchen die Funktion von Drucksinnesorganen beilegt. Für die erstere Hypothese spricht der Bau der Körperchen, ihre Lokalisation und das Ergebnis der Versuche, indem gezeigt werden konnte, dass bei stärkerem Druck in den Gefässen sich die Körperchen aufblähen, während sie bei schwächerem Blutdruck kollabieren.

\section{Zusammenfassung.}

Die Lamellenkörperchen sind aus Hohllamellen (Hohlkapseln) aufgebaut. Jede Lamelle besteht aus zwei bindegewebigen Wandungen, zwischen denen ein spaltförmiger, mit Flüssigkeit gefüllter Raum gelegen ist (Key und Retzius). Die Oberflache der Lamellen ist von flachen Zellen bekleidet. Die Hohllamellen sind einander nur angelagert, nicht miteinander fester verbunden. Infolgedessen können sich $z$ wei benachbarte Lamellen voneinander abheben (wahrscheinlich nur postmortal), wodurch ein Spaltraum entsteht. Die Spaltrăume sind zum Unterschiede von den Lamellenräumen nicht mit Flüssigkeit gefüllt, enthalten auch keine Bindegewebsfibrillen.

Ein elastisches Fasernetz findet sich nicht nur an der Oberflăche der Lamellenkörperchen ( $\mathrm{Michailow}$ ), sondern es konnte ein solches in den Wandungen der drei bis vier aussersten Lamellen nachgewiesen werden.

Der Innenkolben ist ebenso aus Lamellen aufgebaut, wie die nach aussen von ihm gelegenen Anteile des Körperchens (M e r k el). Die Lamellen des Innenkolbens unterscheiden sich aber von den weiter peripher gelegenen dadurch, dass sie nicht geschlossene doppelwandige Röhren darstellen, sondern nur doppelwandige Halbrinnen, die paarweise konzentrisch um den zentralen Achsenzylinder angeordnet sind. Die Kanten der Halblamellen des Innenkolbens sind so orientiert, dass sie in ihrer Gesamtheit entweder einen ganz schmalen Spaltraum jederseits einschliessen, der in der Verlangerung der Schmalseiten des zentralen Achsenzylinders 
gelegen ist; oder es können die Kanten der Halblamellenpaare sich berühren, so dass in der Verlangerung der Schmalseiten des Achsenzylinders eine Art Naht entsteht.

Die im Innenkolben gelegenen Zellkerne sind prinzipiell nicht verschieden von den übrigen an der Oberfläche der Lamellen gelegenen Kernen.

Die dunklere Farbung (am gefarbten Praparat) des Achsenzylinders ist bedingt durch die stärkere Fürbbarkeit der in seinen Lamellenriumen enthaltenen Flüssigkeit und die geringere Weite der Lamellenrăume (dichtere Lagerung der Kapselwände).

Blutgefässe dringen, wie längst bekannt, hauptsächlich in der Gegend des basalen Poles mit den Nerven in die Lamellenkörperchen ein, seltener am distalen Pole oder an anderen Stellen der Oberfläche und bilden im basalen Abschnitt der Körperchen ein schlingenreiches Kapillarnetz, von dem eine Schlinge bis an die Basis des Innenkolbens heranreicht, oder höchstens nur auf eine ganz kurze Strecke in den Anfangsteil des Innenkolbens eindringt. Der Hauptteil des Innenkolbens bleibt (wenigstens bei den Lamellenkörperchen im Mesenterium der Katze) stets gefissfrei. In allen übrigen Teilen des Körperchens können Kapillaren vorkommen.

Bei steigendem Druck in den Gefässen blähen sich die Lamellenkörperchen infolge stärkerer Füllung ihrer Lamellenräume auf; sie năhern sich mehr der Kugelform, wahrend sie für gewöhnlich mehr oder weniger abgeflacht (kollabiert) erscheinen, so dass ihr Dickendurchmesser hinter dem Breitendurchmesser zurücksteht. Die Füllung der Körperchen kann so weit gehen, bis der Dickendurchmesser gleich dem Breitendurchmesser wird. Eine Oberflachenvergrösserung findet hierbei nicht statt.

Eine Aufblahung der Körperchen scheint auch bei stärkerer Durchfeuchtung des dieselben umgebenden Gewebes einzutreten.

Die Anlagerung der Lamellenkörperchen im Mesenterium der Katze an grössere Gefăsse ist eine so innige, dass wahrscheinlich bei starker Füllung der Gefăsse auf die Oberflăche der Körperchen ein Druck ausgeübt wird.

Der Bau, die Lage und die Versuchsergebnisse sprechen dafür, dass die Lamellenkörperchen Blutdruckregulatoren sind.

Wien, Anfang Mărz 1911. 


\section{Literaturverzeichnis.}

1. Grosser, 0.: Zur Anatomie und Entwicklungsgeschichte des Gefässsystems der Chiropteren. Anat. Hefte, H. 5̌5, 1901.

2. Henle, J. und Kölliker, A.: Über die $\mathrm{Pac}$ in i schen Körperchen an den Nerven des Menschen und der Säugetiere. Zürich 1844.

3. Herbst, G.: Die Pacinischen Körper nnd ihre Bedeutung. Ein Beitrag zur Kenntnis der Nervenprimitivfasern. Göttingen 1848.

4. Key, A. und Retzius, G.: Studien in der Anatomie des Nervensystems. Arch. f. mikr. Anat., Bd. 9, 1873.

5. Kölliker, A.: Handbuch der Gewebelehre des Menschen. Bd. I, 1889.

6. Merkel, Fr.: Über die Endigungen der sensiblen Nerven in der Haut der Wirbeltiere. Rostock 1880.

7. Michailow, S.: Die Struktur der typischen Vater-Pacin ischen Körperchen und ihre physiologische Bedeutung. Folia neuro-biolog., Bd. II, 1909.

8. Rainer, Fr. J.: Sur l'existence d'un type geant de corpuscule de P a c in i. Compt. rend. Soc. biol. Paris, T. 67, 1909.

9. Rauber, A.: Untersuchungen über das Vorkommen und die Bedeutung der Va te r schen Körper. München 1867.

10. Retzi us, G.: Die Pacin i schen Kïrperchen in G olg i scher Fürbung. Biolog. Untersuch., N. F., Bd. 6, 1894.

11. Derselbe: Zur Frage von der Endigungsweise der peripherischen sensiblen Nerven. Biolog. Untersuch., N. F., Bd. 8, 1898.

12. v. S ch u ma cher, S.: Über das Glomus coccygeum des Henschen und die Glomeruli caudales der Säugetiere. Arch. f. mikr. Anat., Bd. 71, 1907.

13. Stöhr. Ph.: Lehrbuch der Histologie und mikroskopischen Anatomie des Menschen. 13. Aufl., 1909.

14. Thoma, R.: Über die Abhängigkeit der Bindegewebsneubildung in der Arterienintima von den mechanischen Bedingungen des Blutumlaufes. II. Das Verhalten der Arterien in Amputationsstümpfen. Vir $\mathrm{ch}$ ow s Arch., Bd. 95, 1884.

15. Van de Velde, E.: Die fibrilläre Struktur der Nervenendorgane. Internat. Monatsschr. f. Anat. u. Physiol., Bd. 26, 1909.

\section{Erklärung der Abbildungen auf Tafel VIII.}

(Sämtliche Abbildungen sind mit dem Prisma entworfen.)

Fig. 1. Zentraler Anteil eines Querschnittes durch ein Lamellenkörperchen aus dem Mesenterium einer verbluteten Katze. 10\% Formalin, Del a fi eld sches Hämatoxylin, Eosin. Vergr. 680 fach. $A=$ zentraler Achsenzylinder, $\mathrm{I}=$ Innenkolben, $\mathrm{gS}=$ gemeinsamer Spaltraum, begrenzt von den Kanten der Halblamellen des Innenkolbens und der innersten kontinuierlichen Lamelle, $\mathrm{kL}=$ innerste kontinuierliche Lamelle, $\mathbb{K}=$ Kern im gemeinsamen Spaltraum, $\mathrm{L}=$ Lamellenräume, $\mathrm{S}=$ Spalträume. 
Beiträge zur Kenntnis des Baues und der Funktion etc.

Fig. 2. Zentraler Anteil eines Querschnittes durch ein Lamellenkörperchen aus dem Mesenterium von derselben Katze wie Fig. 1. Behandlung, Vergrösserung und Bezeichnungen wie in Fig. 1. Die Kanten der inneren Halblamellen des Innenkolbens beruhren sich, so dass an dieser Stelle statt eines gemeinsamen Spaltraumes eine Art Naht entsteht.

Fig. 3. Schrägschnitt durch ein Lamellenkörperchen aus der Nähe des Glomus coccygeum eines jungen Weibes. $10 \%$ Formalin, D e l a fi e $1 \mathrm{~d}$ sches Hämatoxylin, Eosin. Vergr. $2 \check{0} 0$ fach. Alle Kapillaren des Lamellenkörperchens enthalten rote Blutkörperchen.

Fig. 4. Längsschnitt (etwas seitlich vom Achsenzylinder) durch ein Lamellenkörperchen aus dem Schwanze eines Macacus rhesus. Zenke rsche Flüssigkeit, D elafield sches Hämatoxylin, Eosin. Vergr. 85 fach. Drei längs getroffene Kapillaren $=\mathrm{K}$ im basalen Achsenteil, mehrere im Bindegewebe eingebettete Querschnitte von Kapillaren in der Gegend des distalen Poles und Durchschnitte durch Kapillaren an verschiedenen anderen Stellen des Körperchens.

Fig. 5, 6, 7 und 8. Lamellenkörperchen aus dem Mesenterium der Katze. Gefässe mit Berlinerblau injiziert; $10 \%$ Formalin mit Xylol aufgehellt, ungefärbt. Vergr. 85 fach. Arterien (= A) dunkelgrau, Venen $(=\mathrm{V})$ und Kapillaren schwarz. Die Abbildungen zeigen die innige Lagebeziehung der Lamellenkörperchen zu den Gefässen. Die Binnengefüsse der Körperchen $(=\mathrm{K}$ ) sind nur in Fig. 7 gut gefüllt, teilweise auch in Fig. 5.

Fig. 5. Zeigt ein Körperchen, das ausser Blutgefüssen auch einem grösseren Lymphgefäss $(=\mathrm{L})$ innig anliegt.

Fig. 6. Zwei unmittelbar einander angelagerte Körperchen. Zwischen den Berïhrungsfl̈chen zieht eine grössere Arterie und Vene.

Fig. 7. In kleiner Entfernung von der Basis des Körperchens sind zwei arterio-venöse Anastomosen (= An) sichtbar. Von dem in der Nähe der Basis des Körperchens gelegenen Kapillarnetz zweigt das Binnengefässnetz des Körperchens $(=\mathrm{K}) \mathrm{ab}$. In diesem erkennt man deutlich eine etwas stärkere Schlinge, die bis zum zentralen Achsenteil des Körperchens reicht.

Fig. 8. Arterie und Vene liegen so innig dem Körperchen an, dass sie dessen Oberflächenkrümmung mitmachen.

Fig. 9. Längsschnitt durch ein Lamellenkörperchen aus dem Mesenterium der Katze. Gefässinjektion mit Berlinerblau. 10\%, Formalin, De 1 a f iel d sches Hämatoxylin, Eosin. Vergr. 170 fach. Reichliche Kapillaren nicht nur im proximalen Achsenteil, sondern auch an anderen Stellen in den Lamellenräumen. $K=$ Kapillarschlinge, die bis gegen die Basis des Innenkolbens reicht. $A=$ zentraler Achsenzylinder, I = Innenkolben, $\mathrm{S}=$ Spaltraum zwischen Innenkolben und innerster kontinuierlicher Lamelle. iL $=$ innerste, dicht gelagerte kontinuierliche Lamellen. 


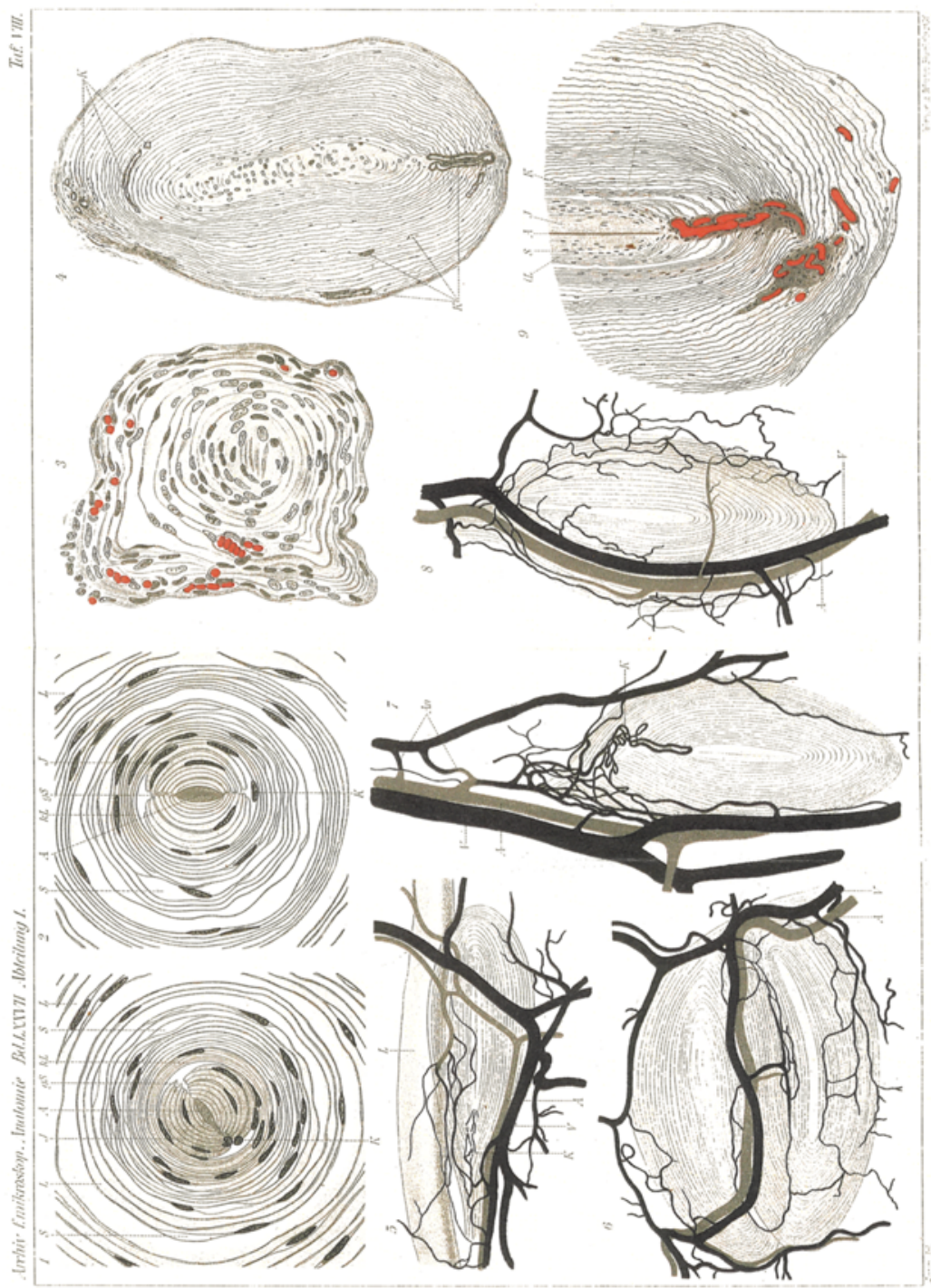

